Science Language Wanted Alive: Through the Dialectical/Dialogical Lens of Vygotsky and the Bakhtin Circle

Wolff-Michael Roth

University of Victoria

\begin{abstract}
Author Note
This research was conducted both at the University of

Victoria and in the Griffith Institute for Educational

Research.
\end{abstract}

Correspondence regarding this article should be addressed to Wolff-Michael Roth, Lansdowne Chair of Applied Cognitive Science, MacLaurin Building A567, University of Victoria, Victoria, BC, V8P 5C2, Canada

Contact:mroth@uvic.ca

The final version was published as: Roth, W.-M. (2014). Science language Wanted Alive: Through the dialectical/dialogical lens of Vygotsky and the Bakhtin circle. Journal of Research in Science Teaching, 51, 1049-1083. 


\begin{abstract}
Over the past two decades, science educators increasingly have become interested in the role of language in the learning of science and have drawn on the work of Bakhtin, among others, for understanding the dialogical nature of knowledge in a sociocultural framework. However, the nature of language and its relation to thinking have not substantially changed and, in many ways, are incommensurable with the cultural-historical, materialist dialectical underpinning of the original framing of the sociocultural and dialogical approaches in the theories of L. S. Vygotsky and M. M. Bakhtin and his circle (e.g., V. N. Vološinov). Most importantly, currently available analyses of science classroom talk do not appear to exhibit sufficient appreciation of the fact that words, statements, and language are living phenomena, that is, they inherently change in speaking. In this paper, I begin by working out the premise that language is a living phenomenon that changes in use. I then present two key insights on language-in-use that derive from the works of Vygotsky and the Bakhtin circle, which are used to develop a theoretical and methodological frame. These key insights and the theoretical aspects of this paper are exemplified with materials from a concept mapping session in a 12th-grade physics course. The proposed model has considerable implications for theorizing the relation between classroom talk and formal written genres of expression, and gives rise to many new research questions.
\end{abstract}

Keywords Vygotsky; Bakhtin; Vološinov; language-in-use; sociocultural theory; sociohistorical theory; dialogism; materialist dialectics. 


\section{Science Language Wanted Alive: Through the Dialectical/Dialogical Lens of Vygotsky and the Bakhtin Circle}

Linguistics studies a living language as if it were a dead language. (Vološinov, 1930, p. 78, emphasis added)

Language develops along with the development of the whole wealth of human activity and intercourse. (Mikhailov, 1980, p. 230)

Although "in much of science education, language is moved to the background or ignored" (Gee, 2005, p. 20), language as a central aspect of science learning has been of increasing interest to science educators for at least two decades (e.g., Lemke, 1990). The turn to language constituted an important paradigms shift, because it allowed science educators to focus on the role of language in understanding (Siry, Ziegler, \& Max, 2012), conceptions (e.g., Ford \& Wargo, 2012), identity (e.g., Kane, 2012), decision-making (e.g., Nielsen, 2012), believes, practices, and discourse (e.g., Richardson-Bruna, Vann, \& Escudero, 2007), nature of science (e.g., Oliveira et al., 2012), knowledge and ability (Lyon, Bunch, \& Shaw, 2012), or learning (Kelly \& Sezen, 2010). In so doing, however, language has been theorized as a tool and medium with the result that "current learning theories tend to take language as a stable feature, permitting access to students' conceptions, identities, or inclinations" (van Eijck \& Roth, 2011, p. 826, emphasis added). This same tendency also has been subject to critique in even more recent studies (Hsu \& Roth, 2012; Roth, 2013a). The most salient expression of treating language as a stable system exists in the specific assumptions that one frequently cited author stated: whereas "the wording of a scientific argument may change ... the semantic pattern, the pattern of relationships of meanings, always stays the same" (Lemke, 1990, p. x). The first introductory quotation is directed against such a conception of language that we commonly find in our field, and the second quotation expresses that language (continually) develops with human activity and intercourse.

The purpose of this article is to reorient the role of language in science education in the 
direction that both opening quotations point by articulating a theory of speech activity that treats language as something alive, and therefore, as continuously changing —including its grammatical and semantic features (i.e., forms of sense, significations, and "meanings"). The theoretical model proposed here, exemplified by extensive case materials, allows us to capture alive not only the dialogic nature of knowing but also its relationship to, and foundation of, individual thinking and continuous change of language.

This paper requires a substantial shift in thinking science language in the way science educators are familiar with. In the first section, I articulate the premise of the argument - a living language changes by the very fact that it is living - and use a classroom excerpt to show that one word, when used again, is the same only apparently. Language as a living, inherently changing phenomenon requires a dialectical/dialogical language theory built on two key insights originally proposed by Vygotsky, Bakhtin, and Vološinov: a word, statement, and language (a) always is a reality for speaker and recipient and (b) changes in use (Section 2). These two insights are articulated in a model that represents them as two irreducible dimensions (Section 3). These insights are then exemplified in the fourth and fifth section, where I, respectively, (a) present the phenomenon of reported speech from one concept-mapping session in a 12th-grade physics course and (b) exhibit how the language-in-use during that concept-mapping session changes over the course of the lesson. I end (a) by highlighting the import of the theoretical framework offered and (b) by sketching implications for science education theory and research.

\section{Language-in-Use is Not Dead and Stable but Alive and therefore Changes}

In science education, language generally and the (scientific) signification ("meaning") of words specifically tend to be taken as rather stable phenomena (van Eijck \& Roth, 2011; Roth, 2008a). In instructional practice, this leads to a focus on science vocabulary that actually kills science language rather than keeping it alive (Richardson-Bruna et al., 2007). Thus, for example, attributing (interview) talk to derive an individual's conceptions, thoughts, or beliefs, which is a common, in the research literature easily verifiable practice in science education, is based on the 
assumption of language as a stable system (Bakhtin, 1975). It is precisely because language is taken as something stable that hybridization of languages - e.g., scientific and home languages of students (e.g., Bellocchi \& Ritchie, 2011; McNeill, 2011; Tomas, Ritchie, \& Tones, 2011)— can be a special phenomenon that occurs in some third space in classrooms where scientific and home cultures intersect. Writing about a specific scientific concept, especially when associating it with the name of a scientist - e.g., "the physics of flight," "Bernoulli's principle," or "homeostasis" (e.g., Falk \& Needham, 2011) — tends to treat the associated discourse as stable until another scientific revolution changes it (Kuhn, 1970; van Eijck \& Roth, 2011). Taking language as a stable phenomenon, however, is problematic because (a) not only do public socioscientific and technological language continuously change (Bakhtin, 1990) (b) but also students participate in the very production of this cultural-historical change (Roth, 2013a; Zeyer \& Roth, 2013). It is problematic because there is evidence that in the very act of talking science in their classrooms, teachers change their ways of talking, reflecting learning and development in the subject matter itself (Roth, 2010a, 2010b). This phenomenon cannot be theorized within frameworks that take language as a stable phenomenon with fixed syntax (grammar, sentence structure) and semantics (dictionary sense, "meaning") as Lemke (1990) describes it because the "demarcation of a strict boundary between grammar and stylistics . . . is methodologically unproductive and in fact impossible" (Vološinov, 1930, p. 122). Finally, the view of language as a stable phenomenon is problematic because it does not allow us to understand and theorize students' spontaneous production of science talk in areas that they have never thought and talked about before, which means that there are cannot be conceptions in the minds of students that would have generated the talk (e.g., Roth, 2008b).

If language is considered to be alive, however, then every time someone utters a word, language and signification change and new forms of thinking emerge (Vološinov, 1930; Vygotskij, 2005). As Bakhtin (1975) showed, historical changes in language and linguistic forms - e.g., in literature forms such as the novel—can be understood only if each statement in the life of everyday folk language already is thought as embodying such a change. Although 
science educators have shown interest in the work of Bakhtin (e.g., Aguilar, Mortimer, \& Scott, 2010; Ford \& Wargo, 2012; Hsu, 2012; Varelas, Kane, \& Wylie, 2012) or Vološinov (El-Hani \& Mortimer, 2007; Hsu, Roth, Marshall, \& Guenette, 2009; Wells, 2007) for theorizing language, and have come to accept that ideas change, language (discourse) itself is not theorized as a living, that is, forever changing phenomenon but as a unitary language system (practice) into which students are "enculturated" or gain access to (e.g., Varelas, Kane, \& Wylie, 2011). In the entire 2011 volume of JRST, there is only one paper that emphasizes language, including scientific language, as a continuously changing phenomenon (van Eijck \& Roth, 2011); not a single text of the entire 2012 volume of Science Education marks language as an inherently changing phenomenon.

Language-in-use as a living and therefore changing phenomenon is central to the works of Vygotsky and Bakhtin. This aspect has not been retained in the literature-with very few exceptions (e.g., Roth, Ritchie, Hudson, \& Mergard, 2011; van Eijck \& Roth, 2011)—but is essential to understand the real life of language (Bakhtin, 1990; Mikhailov, 1980). Language, as every other aspect of life, changes precisely because it is alive. Stable significations ("meanings") of words, such as definitions in dictionaries, are only lower limits of a language's signifying capacity (Vološinov, 1930; Vygotskij, 2005). To underscore this position, both authors use the same piece of text from the work of the Russian novelist F. Dostoevsky, where six drunken workers utter the same sound-word one after the other. Their example therefore is homologous to the following fragment from the classroom talk of a 12th-grade physics course, where one of the concept words imprinted on slips of paper appears for the first time.

Fragment $1^{1}$

\footnotetext{
${ }^{1}$ The following transcription conventions are used: ,?;.- - punctuation indicates slightly rising, strongly rising, slightly falling, strongly falling, and level intonation; ' ' $v$ - diacritics indicate intonation in the syllable that follows; complementARity - capital letters mark emphasis; ((points)) - double parenthesis enclose transcriber's comments; you=re - equal sign marks linking of sound; [] - square bracket mark overlap between speakers; PHOTON - small capitals refer to paper slips with the corresponding word printed on; (2.46) - where relevant, pause is indicated in seconds; <<impatiently $>$ this $>$ - triangular brackets include transcriber's comments on quality of speech; (??) question marks indicating approximate number of words; $\rightarrow$ - arrow points to turn of interest.
} 


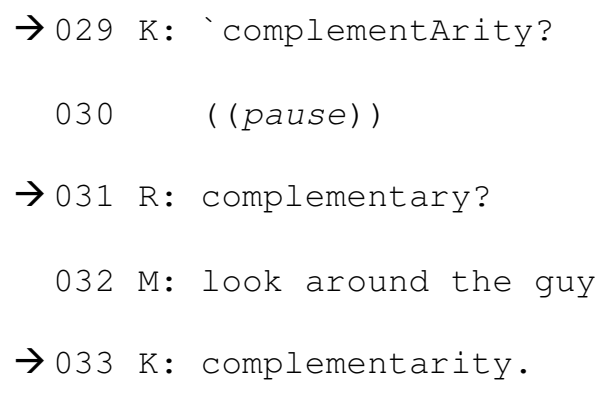

The students are in the middle of a concept mapping session that concludes their unit on the complementary nature of particle and wave picture of light and other electromagnetic phenomena. In fact, the sound-word appears not only once but three times in sequence, interceded by a locution (Miles) that was oriented toward a student in another group (turn 032). (Locution refers to what is said without attributing an intention or effect of what saying something does.) The question that is (almost) never asked in science education concerns the function of such repetition in the evolution of science discourse or what we may be able to learn from such fragments about the nature of language. For example, we note that in all three cases there are not the full propositions — consisting of subject, verb, and object — that teachers might want students to produce (Lemke, 1990; Roth \& Roychoudhury, 1992), but which is an excellent example of predicativity (Vygotskij, 2005). Predicativity refers to a form of abbreviated talk where the psychological subject (i.e., what the idea is about), when given, is omitted and only the predicate is used without repeating the subject to which it is tied (Vološinov, 1930). These words tend to be repeated only in exceptional circumstances, for example, to check the correctness of hearing/understanding. Predicativity is typical of inner speech, which constitutes the bridge between the processes of speaking and thinking; but it also exists in groups of speakers that know each other very well (Vološinov, 1930; Vygotskij, 2005). In public talk it is the equivalent of inner speech, a sociological equivalent of the bridge between fully articulated speech and thinking. But, psychologically, when there is a high level of agreement of thought between interlocutors, then we do in fact observe a shorting of verbal expressions to the point that the significance becomes independent of the word itself fully being expressed in intonation alone. 
Nothing in the original situation denoted here by turns 29, 31, and 33 was the same: It is only when the three sounds are stripped of anything and reduced to "complementarity" that something appears to be constant. A closer look at Fragment 1 shows that the word "complementarity" appears twice as a noun and once as an adjective; moreover, the transcription shows that the intonation changes. It is precisely such intonational changes that lead us to a better understanding of the evolution of language in situation, and, therefore, to the more lasting changes these leave in the (ontogenetic) ability of the students to speak about certain phenomena (Vološinov, 1930; Vygotskij, 2005). When the word first appears (turn 29), we observe an initially falling intonation that modulates a generally rising intonation of the phrase as a whole. Such a rise in a phrase tends to be heard as a question. How the turn is heard in this situation, by other interlocutors, that is, how one or the other interlocutor takes up the word and replies to it, cannot be established on the basis of the locution alone. It requires us to investigate the next locution that gives evidence of the fact that the preceding locution has been taken up at the same time it is being articulated and responded to. Here, following a pause, it is turn 31. But we notice that it, too, is articulated with an overall rising of the intonation in the phrase. There would therefore be a question followed by another question, both implemented by the same word stem. If we have in fact a question-question pair of turns, then the second may be heard as questioning the first, a situation that we might expand by means of the following gloss of a pair of questions: "What is complementarity?" "You are asking me about complementary?" That is, the same (scientific) word stem is used to do very different things.

This brief analysis shows that language-in-use changes and that the "same" word does not "mean" the same when it is repeated. Thus, whereas the lower boundary of signification constitutes a slowly changing dictionary sense of the word, its situated signification may be not related at all to this sense (Vološinov, 1930; Vygotskij, 2005), which requires speakers to continuously generate new, never identical passing theories (Rorty, 1989). Because passing theories are "derived by wit, luck, and wisdom from a private vocabulary and grammar, knowledge of the ways in which people get their points across, and rules of thumb for figuring 
out what deviations are most likely" (Davidson, 1986, p. 446), there is no way of regularizing or teaching this language competency of understanding how a word is currently used. In the next section, I outline the position of Vygotsky and the Bakhtin circle on language as living phenomenon and articulate a model that expresses their dialectical materialist/dialogical approach and present a minimum unit of analysis.

\section{Two Key Insights Concerning Language-in-Use}

Vygotsky and the Bakhtin circle consider language as something living, that is, as something subject to continuous change. The study of language as a living phenomenon requires employing a living cell, a living analytic unit, that is, a unit that reflects the continued becoming of a word that never is the same (Bakhtin, 1990; Vygotskij, 2005). Vygotskij (1983) uses the term category for such units and, to mark that category implies being alive, describes it to be a dramatic event, itself understood in terms of its eventness (Roth, 2013b). This means that researchers must give precedence to the study of syntactic forms over the study of morphological (i.e., form-related) and phonetic (i.e., sound-related) forms typical of linguistics (Vološinov, 1930). There are two fundamental insights in the works of Bakhtin/ Vološinov and Vygotsky that are central to the present reorientation in how to think of language-in-use. I begin by stating these two interrelated and irreducible insights in abridged form and then further develop their contents.

1. A word does not belong to the speaker but always to speaker and recipient simultaneously: "the word is that in our consciousness . . that is absolutely impossible for one person, but that becomes a reality for two" (Vygotskij, 2005, p. 1018). There are two immediate consequences: (a) there is never one "meaning" and (b) there is change in collective act of speaking / receiving. This change finds its expression in the phenomenon of reported speech (exemplified in the section "Reported Speech . .." below).

2. Thinking and speaking are two (ever-changing) processes that manifest, in very different ways, an overarching process: signification. As process, signification and language continuously change (exemplified in the section "Evolution of Classroom Talk ..." 
below).

A word, as Vygotsky suggests, never belongs to one but always is a reality for two. Vološinov (1930) agrees in suggesting that "the individual, as possessor of the contents of his own consciousness, as author of his own thoughts, as the person responsible for his thoughts and feelings - such an individual is a purely socio-ideological phenomenon" (p. 38, emphasis added). This position, therefore, questions all research that attributes thoughts to individual speakers, a presupposition that underlies almost all research currently conducted in science education, whether it concerns beliefs, (mis-) conceptions, attitudes, or emotions. Even researchers who describe their approach as fitting within the conversation analytic tradition, where the turn pair is taken to be an irreducible unit, tend to attribute words and "meanings" to individuals (e.g., Siry et al., 2012); even researchers who describe their approach as fitting within a (Bakhtinian) dialogic tradition take individual statement and ascribe them to the "misunderstandings" of individuals (e.g., Ford \& Wargo, 2012).

The syntactic forms constitute the way in which the discourse of others penetrates a person's speech and how, thereby, older forms of language come to be changed into newer forms in the very process of speaking. This is so because the logic of language is not that of "the repetition of identical forms corresponding to a norm but a constant renewal, individualization of forms in non-reiterable, stylistically unique statements" (p. 58, emphasis added). Thus, according to Vološinov, the macro-development of language lies in its microevolution - the two are but aspects of the same phenomenon: language-in-use. The uptake of the speech of others is in fact central to understanding language as a living phenomenon: at the cultural-historical level, at the scale of individual development, and in the situated functional sense. In its most explicit and immediate way, the uptake of the speech of others occurs in the form of direct and indirect speech, that is, in reporting what others have said precisely in the way they have said it, or, indirectly, by reporting what they have said in the form of a paraphrase and other forms that begin to change the structure of what had been said originally. In the most developed form, the uptake is no longer marked explicitly but exists, for example, in the way we commonly reply to 
what someone else has said. The result is that "as a living socio-ideological entity, as contradictory opinion, language, for the individual consciousness, lies on the border between oneself and the other" (Bakhtin, 1975, p. 106, emphasis added). No language, no word ever is completely our own: always coming from, being for, and returning to the other.

An important aspect of the continuous, never-ending development of language as a culturalhistorical phenomenon and the development of individual speech ability is the uptake of the words and locutions of others for the purpose of developing and supporting the promulgation of our own ideas. It is this uptake that introduces the dialectical moment into the word that makes it, in social interaction, the living and ever changing phenomenon it is. But in its uptake, another's speech comes to be inflected by our own intentions, inflections, evaluations, and intonations. That is, the uptake never is mere reproduction but already transformation of language - in the way that one commodity is exchange-value and use-value simultaneously in the process of the barter exchange (Il'enkov, 1959; Marx/Engels, 1958). The three temporal processes-unfolding conversation, the development of individual speech ability, and the development of language as a cultural-historical phenomenon - are inseparable from each other (Bakhtin, 1975; Roth, 2013c; Vološinov, 1930). It is in and through speech activity that individual speech ability and language as a cultural-historical phenomenon change (Leont'ev, 1969/1971). From this perspective, therefore, every time students are talking science, scientific language changes even if infinitesimally and unnoted: at this instant, as part of the development of individual speech ability, and cultural language as a whole (e.g., Roth, 2010a). Despite its importance, this phenomenon of individual and collective reproduction and transformation is hardly ever studied in any detail. One study of scientific and technological language provides evidence of how local use of science language transforms it on individual and historical scales (Roth, 2013a). Other studies shows how this changing nature of language is reflected in the changing nature of science lectures over historical times (Roth, 2010b) or in a scientific laboratory over the span of about seven years (Roth, in press-b). A third study shows that Swiss students' classroom talk on socioscientific issues reflects Swiss culture and language generally, which allows the authors to 
study post-ecological discourse in the making (Zeyer \& Roth, 2011).

In the phenomenon of reported speech, two voices clearly intermingle: that of the reporting context and the reported speech. A speaker who incorporates or makes reference to the speech of another — which occurs both in quoting and in responding (Roth, 2013d) — hybridizes the syntactical, compositional, and stylistic features of their own and the other's speech (Vološinov, 1930). In direct speech, the grammatical unity of the original speech will be preserved in its entirety, whereas in indirect reported speech, this grammatical unity will disintegrate as the speaker's voice penetrates the original voice; but the latter will never completely disappear. At the inside of discourse, therefore, there is a continuous interaction of the two voices, a continuous and ever-present hybridization (Roth, 2008a), of the narrator's active voice and the voice of the reported (responded-to) speech. But despite consisting of two voices, the unity of the single locution is different than that of two interlocutors in a dialogue, where the respective replies are grammatical distinct.

This phenomenon bears on the reception of the speech of others, that is, apprehension, comprehension, and evaluation that active reception (listening) involves. There are two levels. On the one hand, the locution of another is placed in the context of a commentary; on the other hand, a reply prepares itself. These two moments of active reception are actualized simultaneously in inner speech (Vološinov, 1930). Inner speech is of particular importance because two very different processes characterize it: thinking and speaking (Vygotskij, 2005). It is not simply outer speech minus articulation, but bears characteristics of both. It is therefore the meeting place between the language of the other and individual thought, where the psychological aspects of individual speech (speech ability) come to meet the words of the other. These are the verbal character of outer speech, on the one hand, and the predicative nature of thought, on the other hand. Predicative thought tends to shorten phrases in the direction of retaining the predicate alone at the cost of the subject of the idea unit. The predicative tendency of inner speech actually has the consequence of shortening of outer speech when the other interlocutors already know the subject of the locution. Thus, Vygotsky uses the example of a person being asked the question 
"Would you like a glass of tea?" to which the reply would likely be "No" rather than the more elaborate one "No, I don't want a glass of tea" (p. 990). Similarly, if the interlocutors know the subject of the statement in advance, then shortened speech ("a predicative judgment") tends to be used. Therefore, if the subject is a streetcar (B line), saying "It arrives" or "the B" will suffice to communicate what is happening even without explicitly stating the case, as written text requires it (Vygotskij, 2005).

External verbal speech takes a middle position between writing, on the one hand, and thinking, on the other hand. Whereas oral speech is sometimes predicative-when the subject is previously known or available from the context or available from the intonation-writing is a development in the direction of fully articulated subject and context. The development from oral speech to inner speech and thought goes in the opposite direction, that is, to full predicativity. This is possible because, in thought, the subject of the matter is always known so that thinking can be purely predicative in nature. In dialogue, predicativity leads to a simplification of syntax and peculiar syntactic structures peculiar to speech (Vygotskij, 2005). Vygotsky suggests that as inner speech reaches towards thought, the simplification becomes absolute to the point of complete abandonment of syntactic structure and total condensation of thought.

\section{A Model and Minimum Analytic Unit of Language-in-Use}

In the preceding section, I articulate the suggestion that language remains alive only when the unit of analysis is a living one. Two insights in the works of Bakhtin/ Vološinov and Vygotsky are central to the present reconceptualization of language and the associated method of investigating language-in-use in science classrooms: a word, a statement, and a language (a) always belongs to speaker and recipient simultaneously and (b) develops in the very act of speaking. We may represent the resulting theory in a unit of analysis that contains both the synchronous dimension involved in the production of the sound-word and its active reception, on the one hand, and the diachronous dimension of the response, which ranges from active reception 
to the actual production of a reply (Figure 1). ${ }^{2}$ This model constitutes an irreducible minimum unit of analysis that spans across speakers/recipients and time. This spanning is captured by the adjectives dialectical and dialogical, which denote that the phenomenon so characterized manifests itself in different ways (e.g., as different "understandings" attributed to individuals, and as knowledge structures). Immediately, there are two substantive consequences that change how research has to be done. First, the minimum unit pertains to both participants involved so that it is impossible to attribute the sense or signification ("meaning") of speech to one individual. Second, time is internal rather than external to the unit of analysis, with the consequence that speaking means change. These two aspects - the word as belonging to two participants and the word as changing in use - constitute the proposed model as a radical departure from common theoretical and methodological practice in science education.

\section{««««" Insert Figure 1 about here "»"»")»}

First, the model acknowledges the fact that language generally and each statement specifically is a sociological phenomenon: it captures both the production of the sound-word and its active reception (uptake, evaluation). The individual word always is a reality for two, even when writing for oneself, because "to write for oneself - means to relate to oneself as to another" (Vygotskij, 2005, p. 1022). In the unfolding conversation each word simultaneously belongs to both: speaker and recipient (Vološinov, 1930). This fact is captured in the vertical, synchronic dimension of Figure 1. The individual statement is a sociological unit spread across speaker, who expresses an idea, and recipient, who simultaneously takes up this idea (Vygotskij, 2005). The response, from active reception at the level of inner speech to the externally delivered reply, constitutes the process by means of which thought accomplishes itself.

Second, the nature of the response makes time internal to the unit. This is so because the respondent actively receives the word(s) that some first speaker articulated. ${ }^{3}$ This reception

\footnotetext{
${ }^{2}$ Even an apparently first turn is in response to a situation and thus not a first (Waldenfels, 2006). Thus, in turn 29, Ken articulates "complementarity?" in reply to the situation, which he has actively received.

${ }^{3}$ Ralf, who eventually replies, has to actively receive the word as the first constitutive moment of responding, which is accomplishes itself in the reply: "complementary?," turn 31.
} 
transitions into to the verbal articulation of the second speaker ("reply"). The reply thereby provides an indication of how the initial locution was received, elaborated, and evaluated in the recipient context. The response is the transition from the active reception to the actual reply (Roth, 2013d; Waldenfels, 2006). As transition, therefore, the response is not the same at the beginning and at the ending: it is non-self-identical, heterogeneous, hybridized. Responding constitutes the psychological-developmental dimension of speech. This movement from thought to word is a process that describes a functional development in the situation. The transitional movement from thought to word constitutes a form of development peaking (Merleau-Ponty, 1945; Vygotskij, 2005). Thought does not merely externalize itself in the form of words: It becomes what it is only in s. This process of becoming, for Vygotsky, constitutes the (contradictory) unity of the non-being and being of thought.

Both aspects, statement and response, therefore, are diastatic processes: they are spread out, non-self-identical and thus internally contradictory in a dialectical/dialogical sense. The individual statement involves simultaneous replying and actively receiving; the response involves diachronous active receiving and replying. In this model (Figure 1), the minimum unit of analysis, the movement and change of sense (theme) and language are built in. The individual word is non-self-identical, for it is different for the speaker and the active listener neither of whom owns it; it is not only different but also (further) transformed in the course of the response, where it comes to be elaborated by social commentary and evaluation.

The foregoing has substantive methodological consequences. Researchers interested in understanding the inner dynamic of a conversation - rather than make up ("construct") what each speaker independently means - have to hear the next turn, the one that picks up on the second appearance of complementarity (Bakhtin, 1975; Schegloff, 2007). We find this in turn 33 of Fragment 1, which repeats the noun form (complementarity) of turn 29. But this time the intonation is falling strongly, which is normally heard as a constative (i.e., as a factual statement regarded to be true or false). That is, because in turns 29 and 33 we hear the same speaker, we may expand our gloss in this way: "Yes, I am asking you about complementarity." Although we 
have the stem of the same word produced three times in sequence, the situated signification that is sometimes referred to as theme (tema, Vološinov, 1930) or sense (smysl, Vygotskij, 2005) is different and always changing. Whereas in its first appearance, it ultimately came to be reified in the turn taking as a question about the nature of the word; in its second appearance, it became reified as a question about a question, the second making the first problematic. We therefore learn from this little exchange that the inner movement of the classroom talk is given immediately when we consider pairs of turns, which are linked to each other because these are parts of a whole. The relations that exist between rejoinders in dialogue-e.g., question-reply, assertion-objection, invitation-acceptance/rejection, etc. - do not exist among the units of language that linguists identify (Bakhtin, 1979). Such relations exist between the locutions of different speakers, who presuppose each other in the verbal exchange. That is, to understand dialogue and its evolution - which in turn leads to the development of the speech ability of individual speakers (Leont'ev, 1969/1971) — requires us to analyze pairs of turns.

\section{Reported Speech in a Concept-Mapping Session}

An integral aspect of the first main insight is the fact that the uptake of another's word constitutes the central mechanism in a sociological approach to the problem of continuous language evolution (Vološinov, 1930). Besides responding, specific forms of uptake of another's word include direct speech (quoting), indirect speech, and quasi-(in)direct speech. The uptake also expresses the responsive position to the preceding locution-agreement, disagreement, execution (if it is an order), evaluation, and so forth (Bakhtin, 1979). Although the discussion of these speech genres constitutes one-third of Vološinov's book, this aspect - though central to the very theory of cultural-historical, individual developmental, and situational evolutionary changes in language - has not been taken up (to the best of my knowledge) in the science education literature. The various forms of the uptake of the words of others in a concept-mapping session are exemplified in the following analysis of lesson fragments.

The fragments used to exemplify the approach to language as a living, ever-changing 
phenomenon are part of a database of 50 concept-mapping sessions videotaped in 11 th- and 12th- grade physics courses that I had taught at a private high school in central Canada over a two-year period. The students in this school tended to come from affluent families, though some of these families had started out as members of the working class. The enrolment of less affluent students was made possible by scholarships. In terms of ability levels, the student body was not different from nearby local public high schools. Following each unit, students completed individual concept maps as homework in which they linked all those words that appeared in boldface in their relevant textbook chapter. They collaboratively produced concept maps in small groups of 3-4 students during class time as part of my explicit strategy to implement a call for engaging students in the active talking of science (Lemke, 1990). Although any one of these sessions could have been used as example, I chose this specific one because the students represent all achievement levels and because the entire transcription of this lesson is available in the literature (Roth, 2009, pp. 294-312). The three Euro-Canadian students appearing in the excerpts represented the top (Ralf), middle (Miles), and bottom achievement levels (Ken) of the graduating class. The task took 38 minutes and a total of 669 turns; the turn numbers used here are those that appear in the fully published transcription of the lesson numbered from 1 to 563 . The concept map-related talk abruptly shifted three times (51 turns: 136a-136h; 331a-331s; 426a-426aa) to the topic of racism - one student charging another one, with a simultaneously joking and serious overtone- - but without apparent effect on the talk about the scientific concepts. (Further, more detailed ethnographic descriptions of the background are provided in Roth, 2009.) The analyses have been conducted implementing the minimum unit of analysis presented above (Figure 1), which does not allow attribution of a word to an individual and where speaking/receiving are two sides of the same phenomenon. The analyses implement two fundamental directives. First, conversations are irreducible societal phenomena and therefore require minimum units of analysis that reflect society (Durkheim, 1919; Vygotskij, 2005). Second, only what is available to everyone in the setting (here the students and their teacher) can explain the internal dynamic of language-in-interaction (Garfinkel \& Sacks, 1986; Roth, 2013e). 
The consequence is that researchers have to use the same interpretive methods as the participants; no special research methods therefore are required and in need of explication (Garfinkel, 1967). What is required, though, is familiarity with the ongoing cultural-historical activity and associated language, which form a unit that pragmatist language philosophers refer to as language game (Rorty, 1989; Wittgenstein, 1953/1997).

In Fragment 2, the first locution (turn 252) explicitly marks as having part of its origin in what others have said. First, the locution refers to something Ken's addressee, the teacher ("you"), has said: "You're giving us that example with the phonons." Second, the phrase links this first report of someone else's speech to another report, now something that another group member, Ralf, has said: "that waves also have a lower detailed description within itself." The second report is what we know as indirect speech, what has originally been said is somewhat transformed rather than constituting the precise words of the other. In the first example, on the other hand, we no longer get a sense of what the person referred to has said other than there was an example with phonons. In this case, the transformation is more extensive than in the second case.

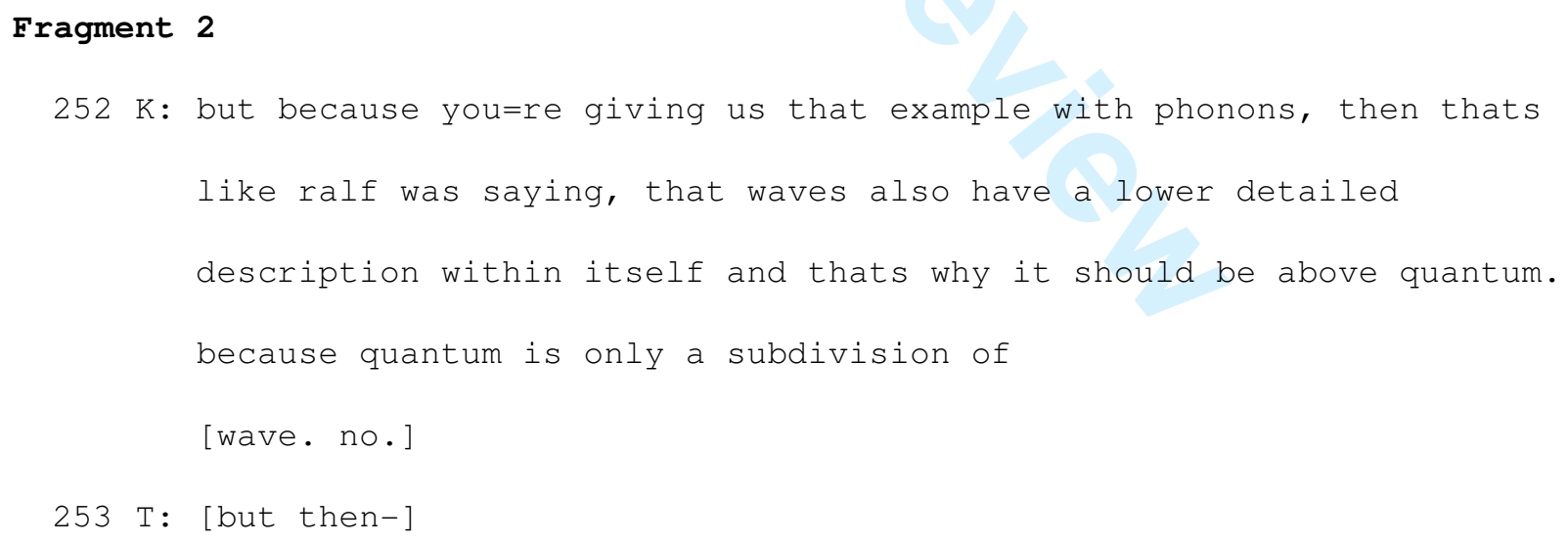

In the present situation, Ken offers up a proposal for the placement of WAVE above QUANTUM in the overall map: the referent of "it," wave(s), should be above quantum. There is a further elaboration, which in fact anticipates a potential query or critique in that the statement provides a reason for the placement: "because quantum is only a subdivision of wave." Thus, in this 
locution that has the length of a paragraph, which is one of the longer statements in the entire transcript from this lesson, we observe a form of argument. What the teacher has said previously now is mobilized as the premise; it is followed by an implication that draws on something that a peer has said. The statement then articulates the central point, before providing another reason in support of the proposal. That is, we have a concrete example of Bakhtin's description of how the language of others becomes our own in the course of deploying it for our own intentions. The language, therefore, is both our own and the other's; it is alive in the very trajectory that takes the word from the other, to us, and, in our addressing the other, it returns to him/her.

That a transformation of the speech of the other has occurred, we can observe in the first of the two cases, where Ken's statement points to a part of the classroom talk in which the teacher had introduced some talk about phonons as another instance of a quantized wave phenomenon. The teacher in fact did more than introduce the talk. He had left the classroom to get another book from his office within steps of the group. Returning with the book, he has opened the page and points to it (turn 196). All three students orient to the page that is about phonons (see figure in turn 203). The students then reorient to their task discussing the duality of electromagnetic waves. It is at this point that the teacher enters the conversation again, pointing to the page, articulating the contents in his own words: "phonons are elastic waves, which are quantized but it's an elastic wave in matter, it's not like, it's inside a crystal, but the molecules can move" (turn 203). We observe an uptake of this talk in a statement that follows: "so a phonon ... is a form of quantum energy" (turns 204, 206). Here, the original statement "phonons . . a are quantized" appears in a transformed and elaborated form. There is an immediate positive evaluation, "Yea, that's right" and an acknowledgment of understanding on the part of the student: "Yea, that's it."

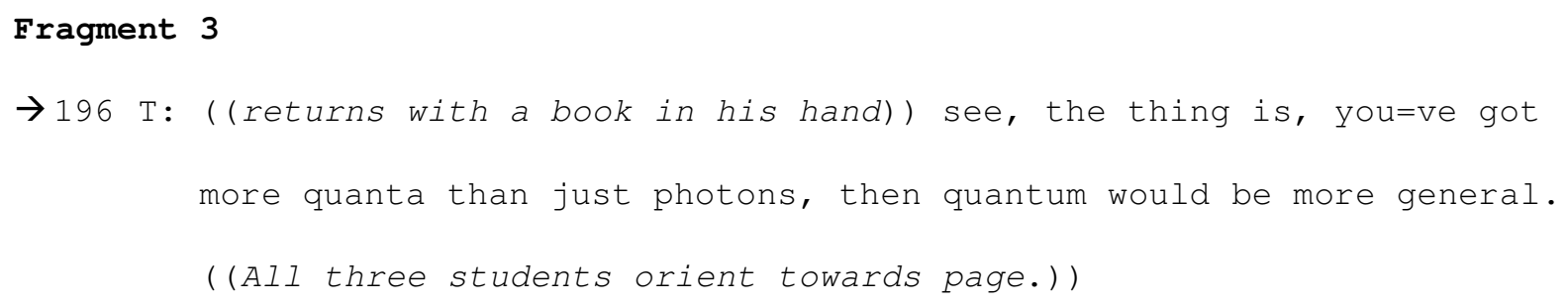




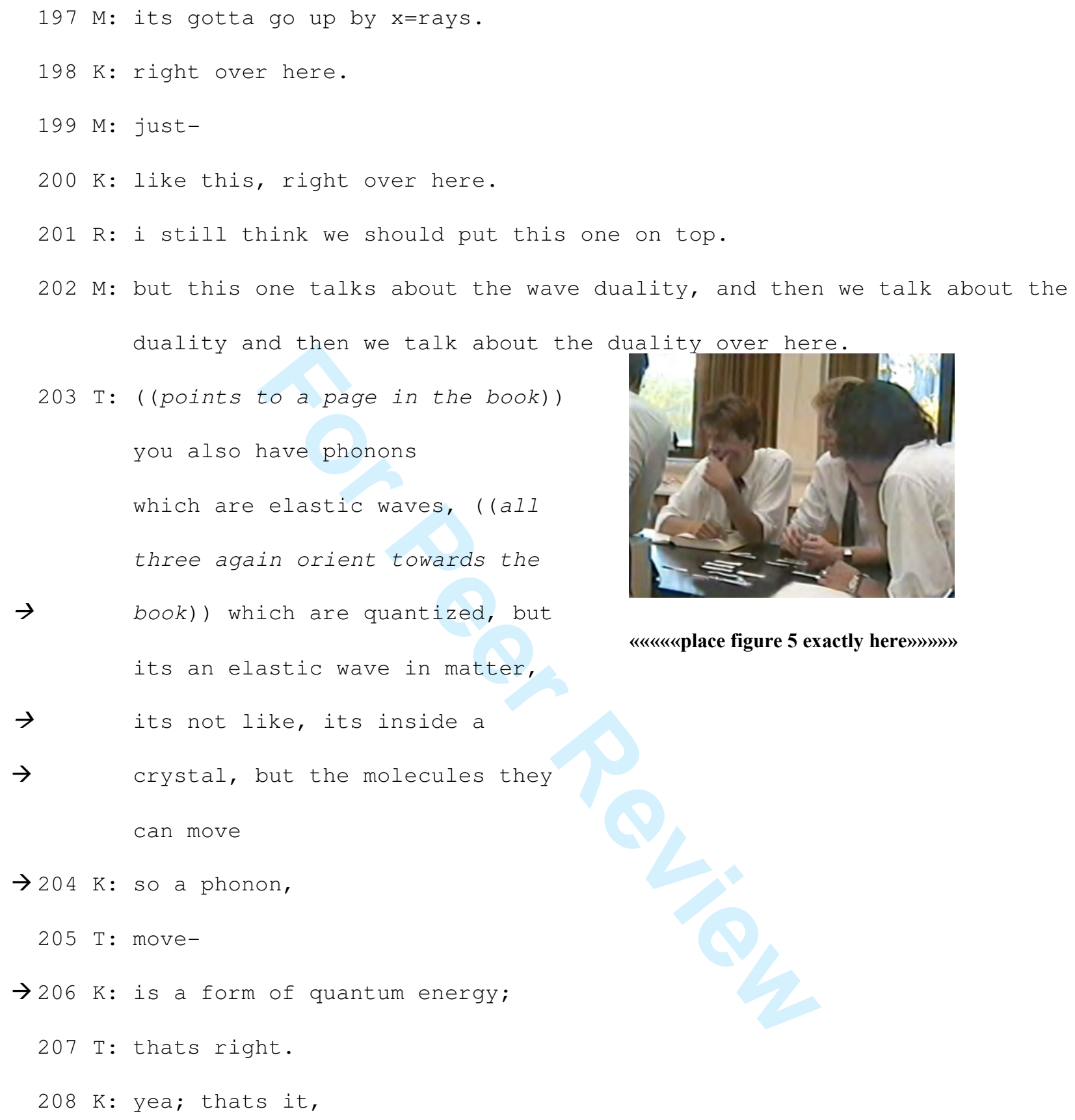

Fragment 4 shows that the transition between direct and indirect speech is sliding — and therefore in movement. Although the students do not use "that" to separate the verb "to say" from the reported speech, the statements do not imply that Einstein and Planck have actually used those words that the students ascribe to them-e.g., "Einstein said it has a certain energy"). The prosodic parameters intonation and speech intensity (Figure 2) show that the articulation is 
typical for the indirect speech, which does not set the quoted passage apart in the way it does for a direct reported passage (Figure 3, below) (Roth, 2010a; in press-a). Here, speech attributed to two eminent physicists A. Einstein and M. Planck, is used indirectly in advancing certain statements about the relationship between the terms quantum, which has a certain energy $(E=$ $\mathrm{h} \cdot f$ ), and photon. The attributions are important, because these are tied to the distinctions made between the respective terms and because of the discursive repertoire that mobilizes authorities in the attempt to convince others (Hsu \& Roth, 2012; Roth \& Lucas, 1997). On the one hand, Planck is said to have attributed a certain energy level to the quantum (turn 189), but Einstein is said to have introduced the term photon for a quantum of light. Whereas the attribution to certain figures might function to gain the upper hand, here the two interlocutors, Ralf and Miles, each mobilizes an eminent physicist, both of whom were involved in the revolution of the quantum nature of light. (Einstein described the photoelectric effect and Planck used the quantum to explain the radiation spectrum from a black body.)

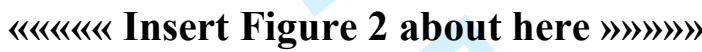

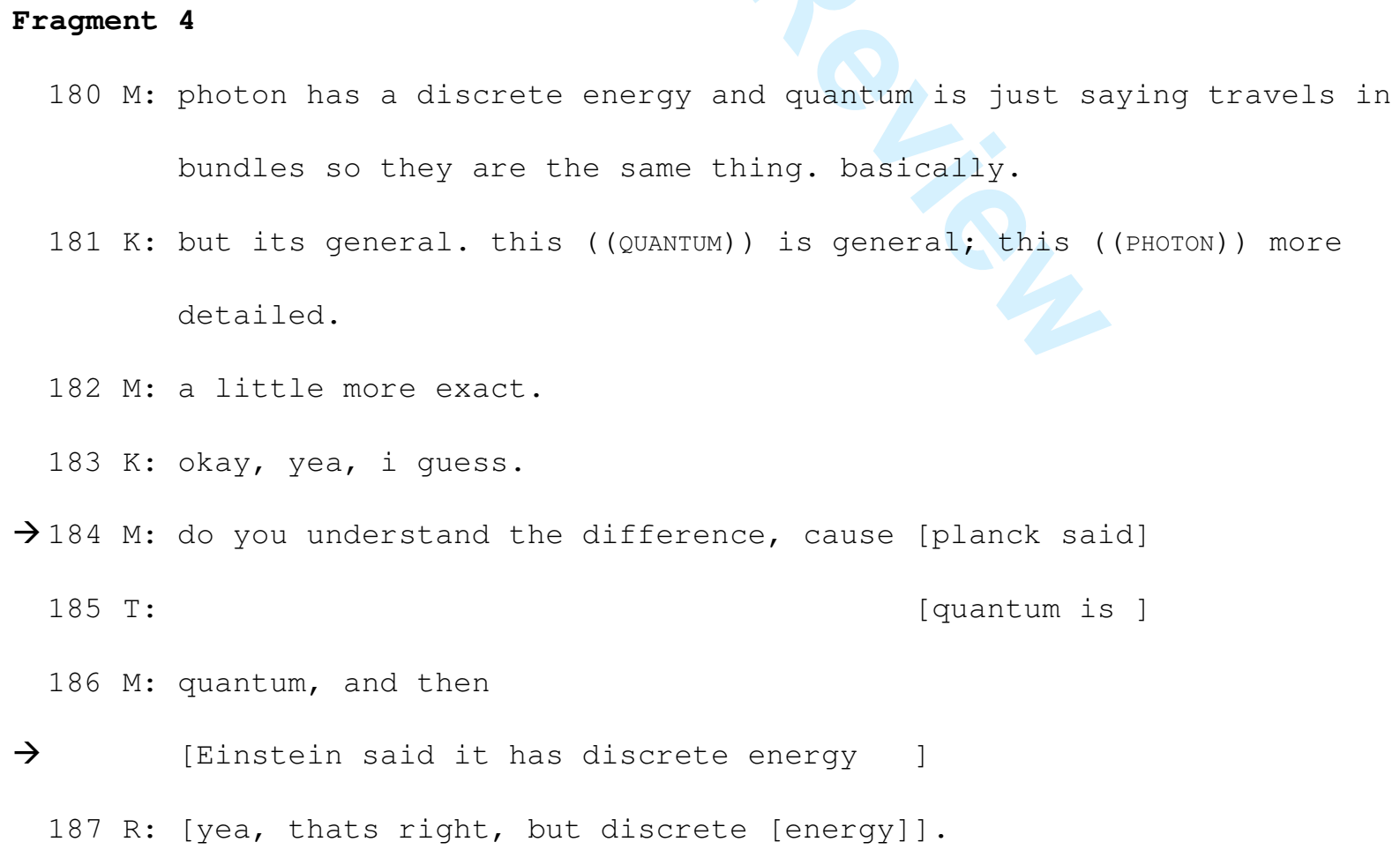




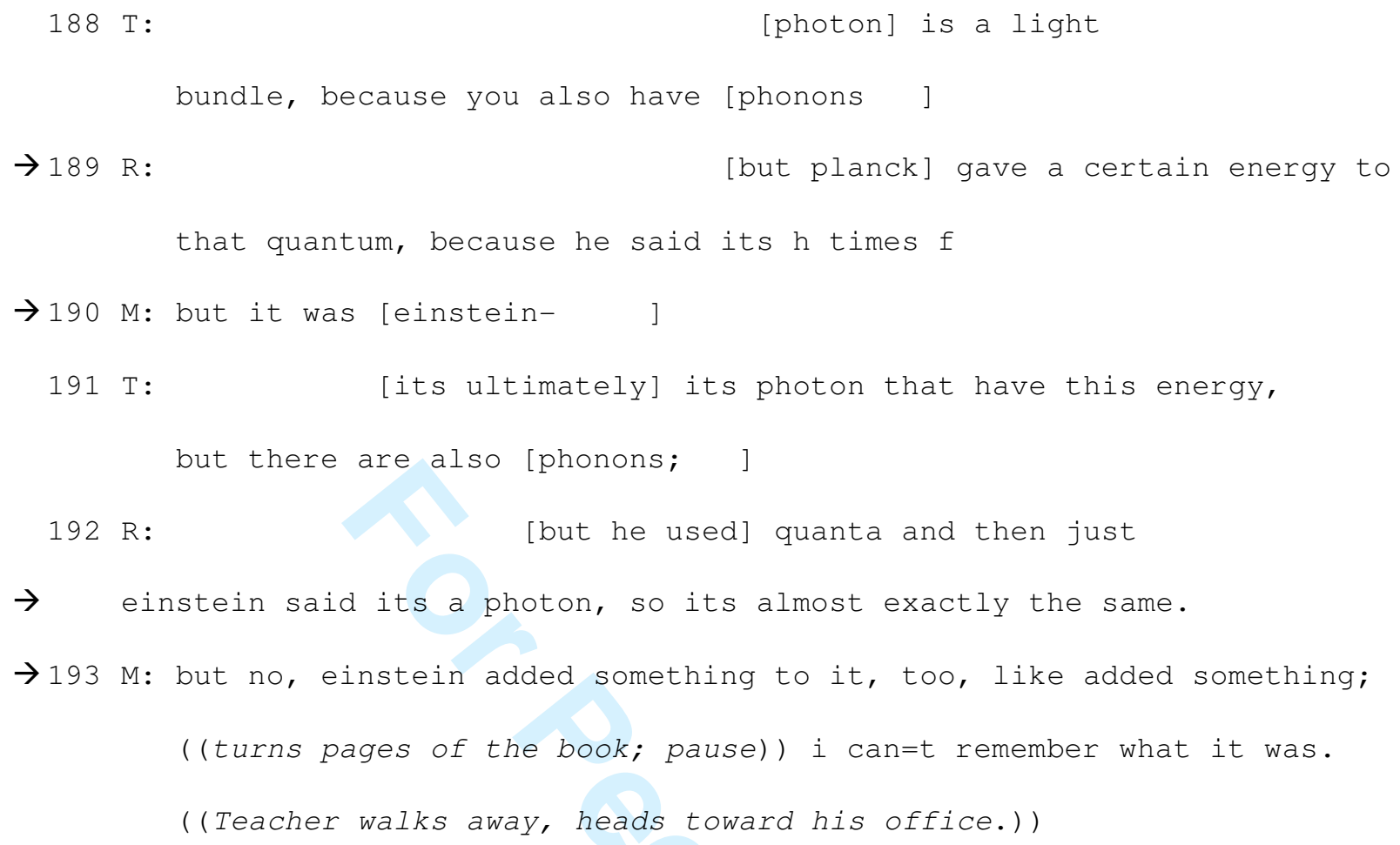

In Fragment 5, we see how the indirect reported speech may involve considerable transformation of the words that have actually been said before. Here, in Miles' locution (turn 163), we find the grammatical construction of indirect reported speech: "he's saying [that] we should pop light on top and have complementarity." In fact, depending on the intonation and under different conditions, this could have been heard as quasi-direct reported speech. The latter is a grammatical construction found in literary language, where an original "you should pop light on top and have complementarity" is changed to "we should pop light on top and have complementarity." Quasi-direct reported speech, which is a mixture between direct and indirect speech, is characterized by a tone and word order typical of direct discourse and tenses and persons of verbs from indirect discourse (Vološinov, 1930). This grammatical form "permits another's inner speech to merge, in an organic and structured way, with the authorial context" (Bakhtin, 1975, p. 133). The episode is introduced by a statement of what it is that the interlocutors "are talking about," where the locution, in the voice of the teacher, resumes what has been said immediately preceding the turn. We first observe a take-up of the topic in the 
locutions of Ken (turns 158, 160), before Miles, who can be heard to start saying something involving the same referent subject ("so, he ..."), is stating what the teacher can be heard to have said (turn 163).

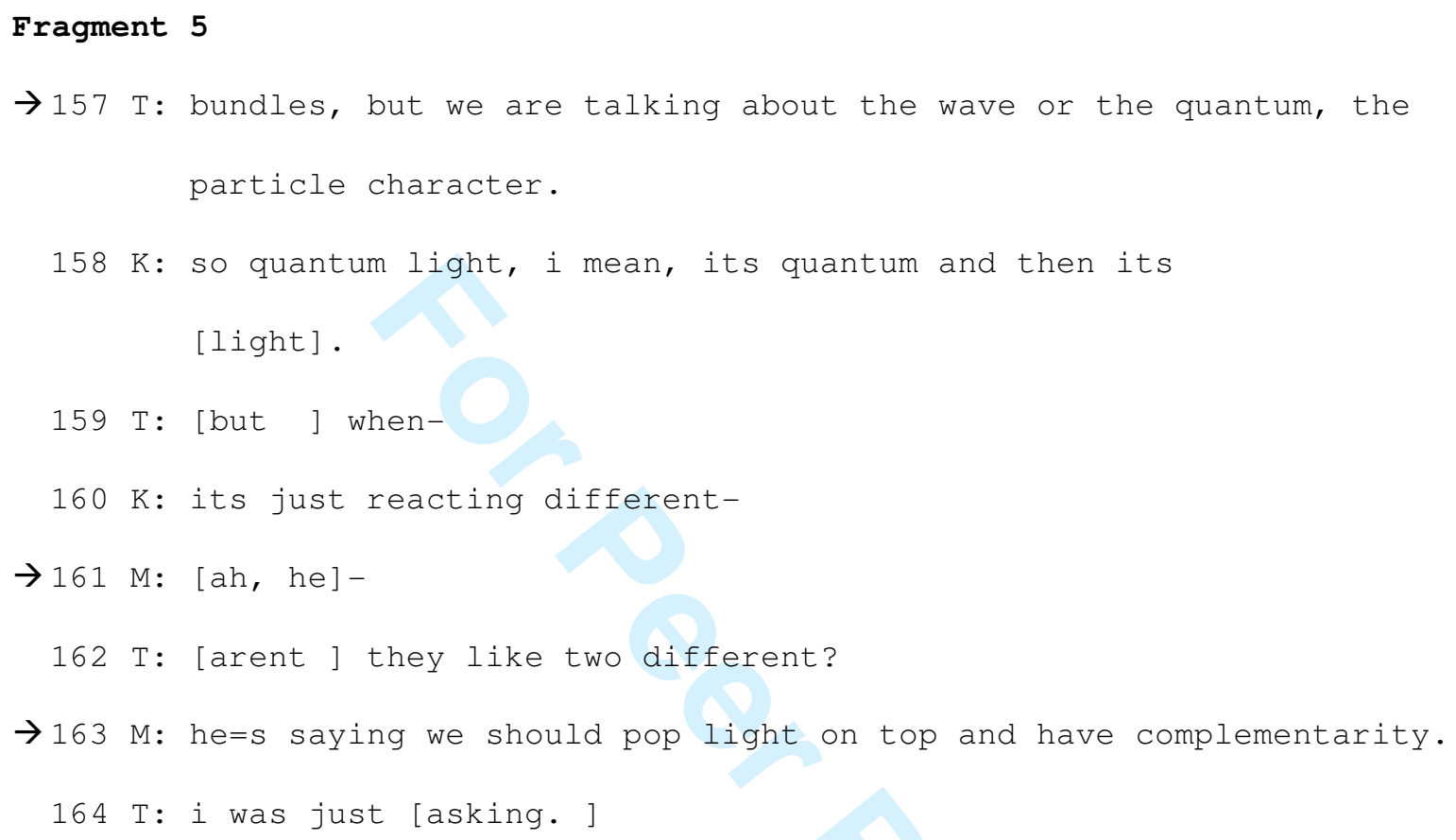

Comparing turns 157 and 163, it is apparent that the statements differ. But the second one reflects one of the possible ways in which one may report what the teacher really can be heard to have said without saying it in so many words. It is a transformation that moves ahead the topic specifically and the conversation more generally. It creates a new situation that the interlocutors now are confronted with. There is an immediate uptake, which expresses itself when the teacher can be heard to be protesting in the sense that he states having asked a question rather than said what the students ought to be doing.

In Fragment 6, it is actually the teacher who uses direct speech to bring into the conversation a phrase that also can be found in the book. Pointing directly to the place on the relevant page in the book, the teacher utters: "See it says particle-like entity or quantum" and adds, "which, [is] a photon." He then elaborates, "but you can also have phonons" (turn 247). As Figure 3 shows, we observe shifts in the pitch that is typical for direct discourse: following the indication that flags a 
quotation to come "see it says," there is a jump in the pitch level (from $141 \mathrm{~Hz}$ to $215 \mathrm{~Hz}$ ), with a falling intonation of what the quoted passage says, and a considerably slower speech rate than during the reporting speech (from 6.37 syllables/s to 4.66 syllables /s) (Roth, 2010a). The episode ends with the previously analyzed turns 252-253.

\section{«"«"«" Insert Figure 3 about here "॥"»"»)}

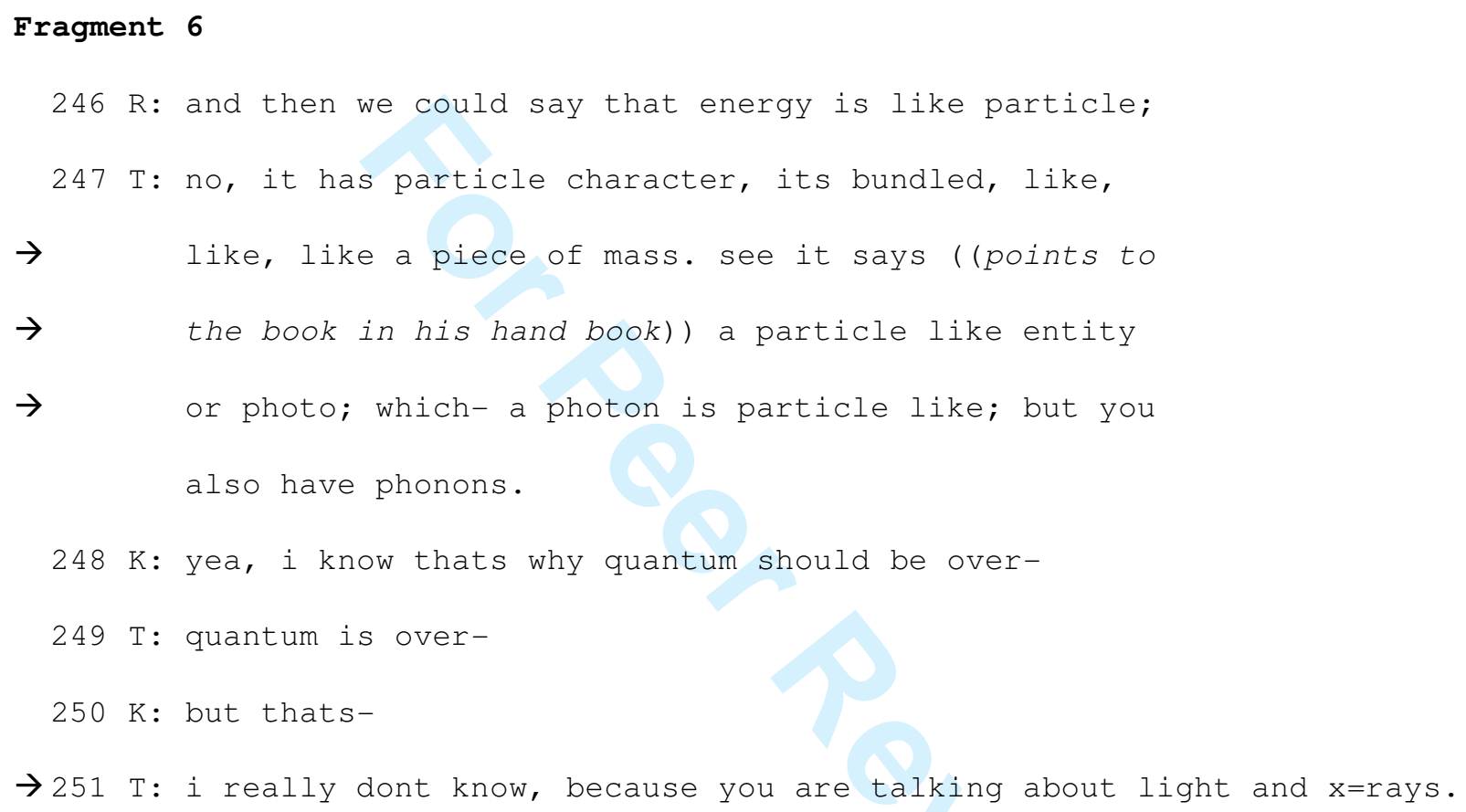

Another way of reporting someone else's words is introduced by the verb "to talk about." This allows the speaker to articulate what a stretch of conversation was about without actually saying what each speaker has said. In Fragment 7, the teacher offers an invitation to students to report what the chapters have been about. That is, it is unlikely that he invites students to directly quote the entire chapter. Rather, he invites them to state in just so many words the content, gist, or principle of ideas. We see precisely that to be occurring: the teacher provides a positive evaluation after Ralf, using the syntactical structure of indirect speech (which prefaces the reported speech by "that"), says "the duality of wave" (turn 77).

Fragment 7

072 R: concept; 


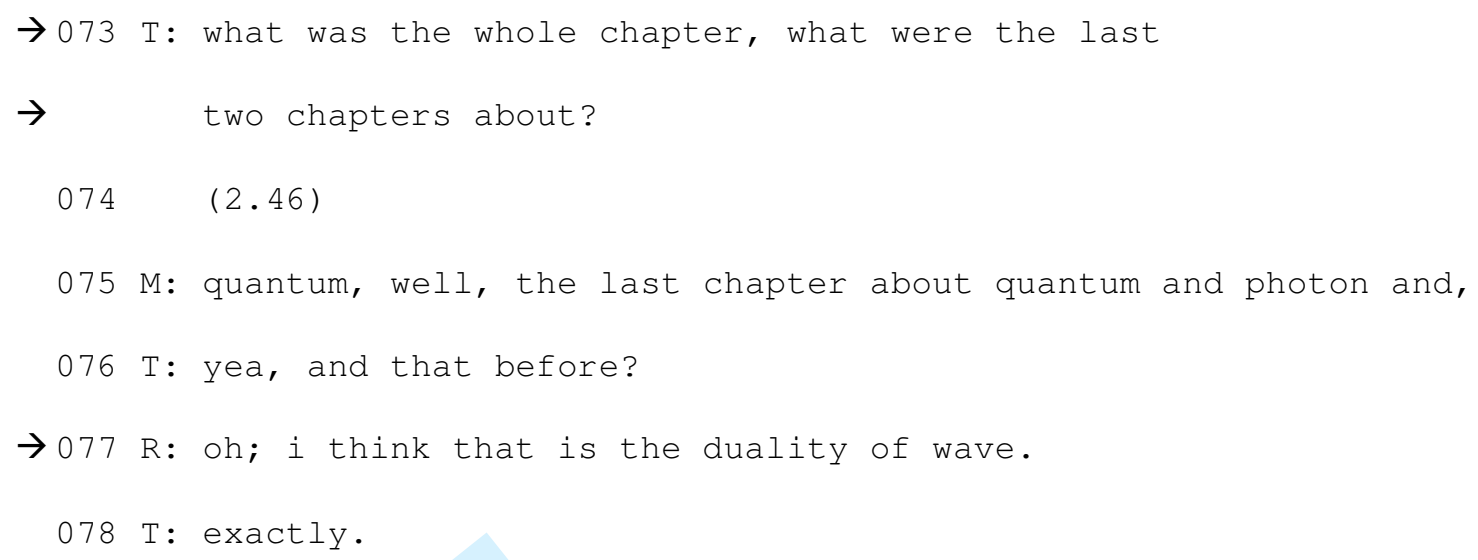

In this form, the contributions of a number of speakers can be integrated into the same statement, which the speaker mobilizes for his intention, for example, to delimit topical contributions from non-topical contributions. In Fragment 8, Miles directly excludes (turn 227) what Ralph has said before ("there are more waves than there are quanta," turn 224), attributing the contribution of the latter to be outside of the topic ("we are not talking about what one is more," turn 227). The statement says that what they are really talking about is the equal status (of QUANTUM and WAVE). The locution uses direct quotation with the same function. Ken's turn introduces the direct reported speech "wave," he repeats that "wave" is all that the sheet says; and he further states what the text on the sheet does not say: "light wave" (turn 228).

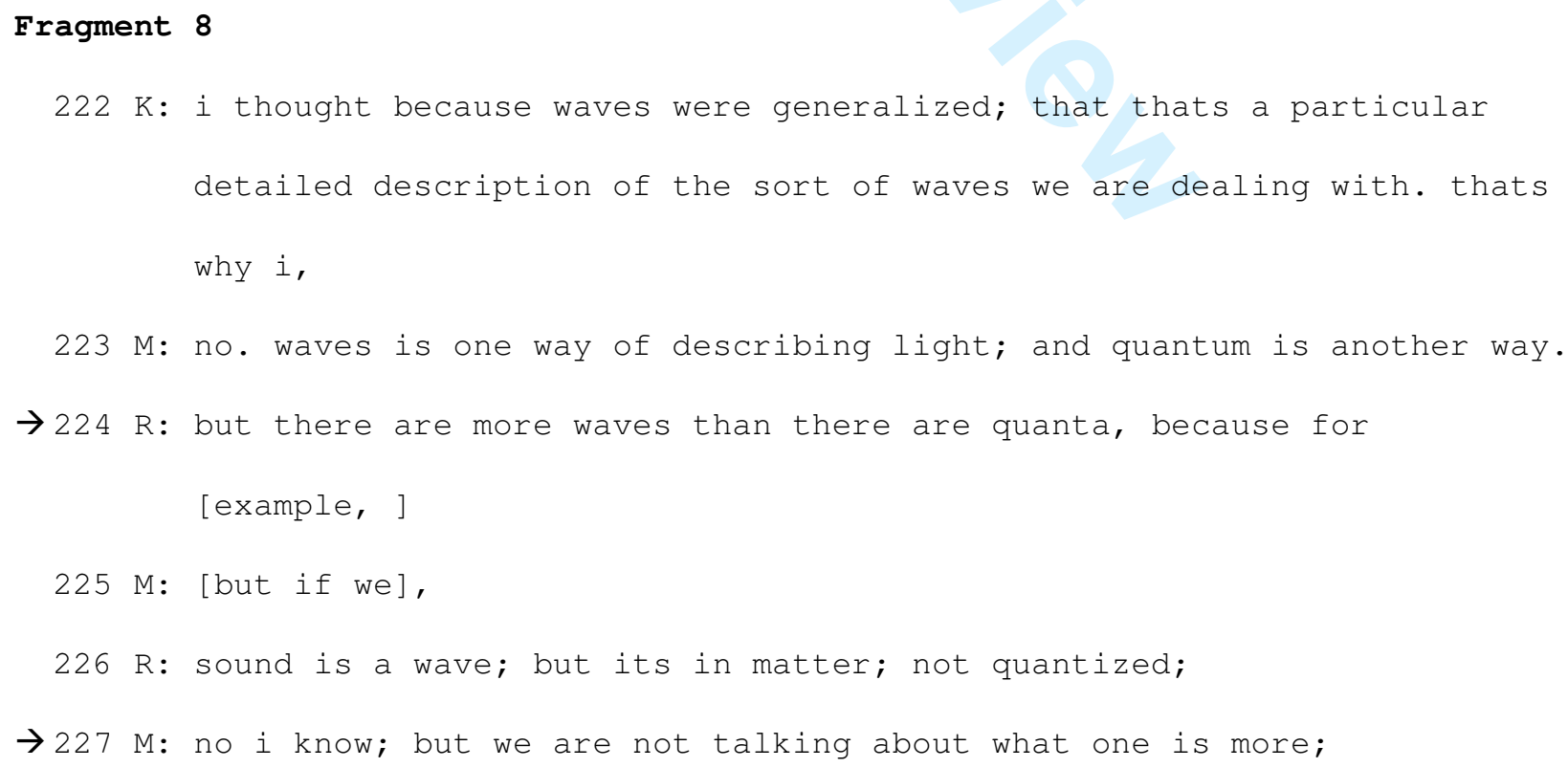




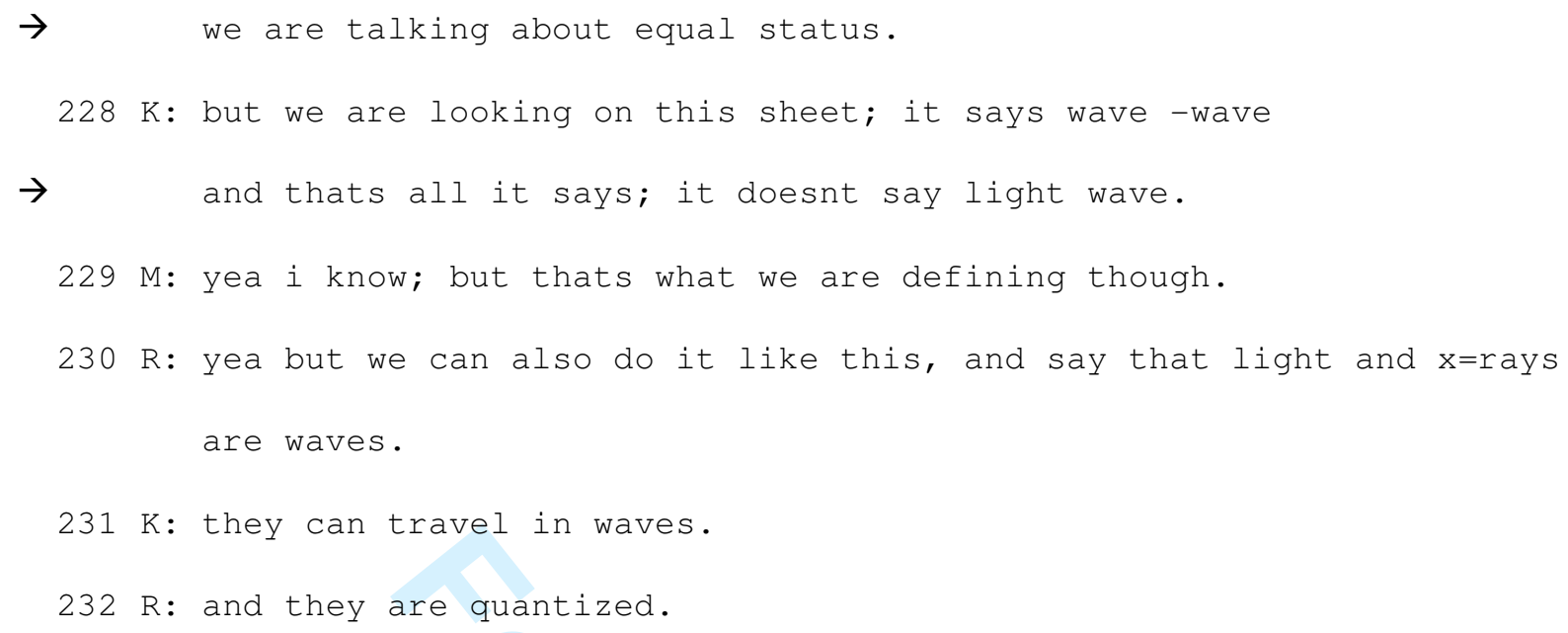

Rather than quoting or paraphrasing another person, an expression such as "I mean" may be used to flag that a new and different statement really is saying the same thing as before. In the 38-minute session recorded, there are 14 instances where this expression is used to say the same in different words. But, as such, what has actually been said so far, "the Said" (Roth, 2013d), has changed by the fact that the second instantiation of an idea constitutes an elaboration; a text and its elaboration now constitutes a new text that is more than what the text has been. In Fragment 9, turn 7 constitutes a statement concludes a series of statements concerning the term "quantum." Turn 7 completes a statement about the quantum as the singular form, which has quanta as its plural. The first part of the turn that concludes this pair is an acceptance and acknowledgment of the preceding: "I see what you mean" (turn 7). The locution continues producing a statement that can be heard as articulating what has previously been acknowledged as having been meant: "wave and quantum are an instant" (turn 8). (The next turn then takes up both terms, wave and quantum, and produces, by means of connective "is part of," a new statement.) Here, the phrase "I see what you mean" flags that what follows is a restatement and transformation of what has been said before. In this instance, the transformation occurs across two speakers, one transforming what another one has said. But the same expression may occur within a locution, allowing a speaker to transform what s/he has said. In Fragment 10, the teacher first utters a statement about WAVE and QUANTUM appearing at the same level and then marks that he meant 
to say before: presumably that "wave" is more general than "light wave" (turn 209).

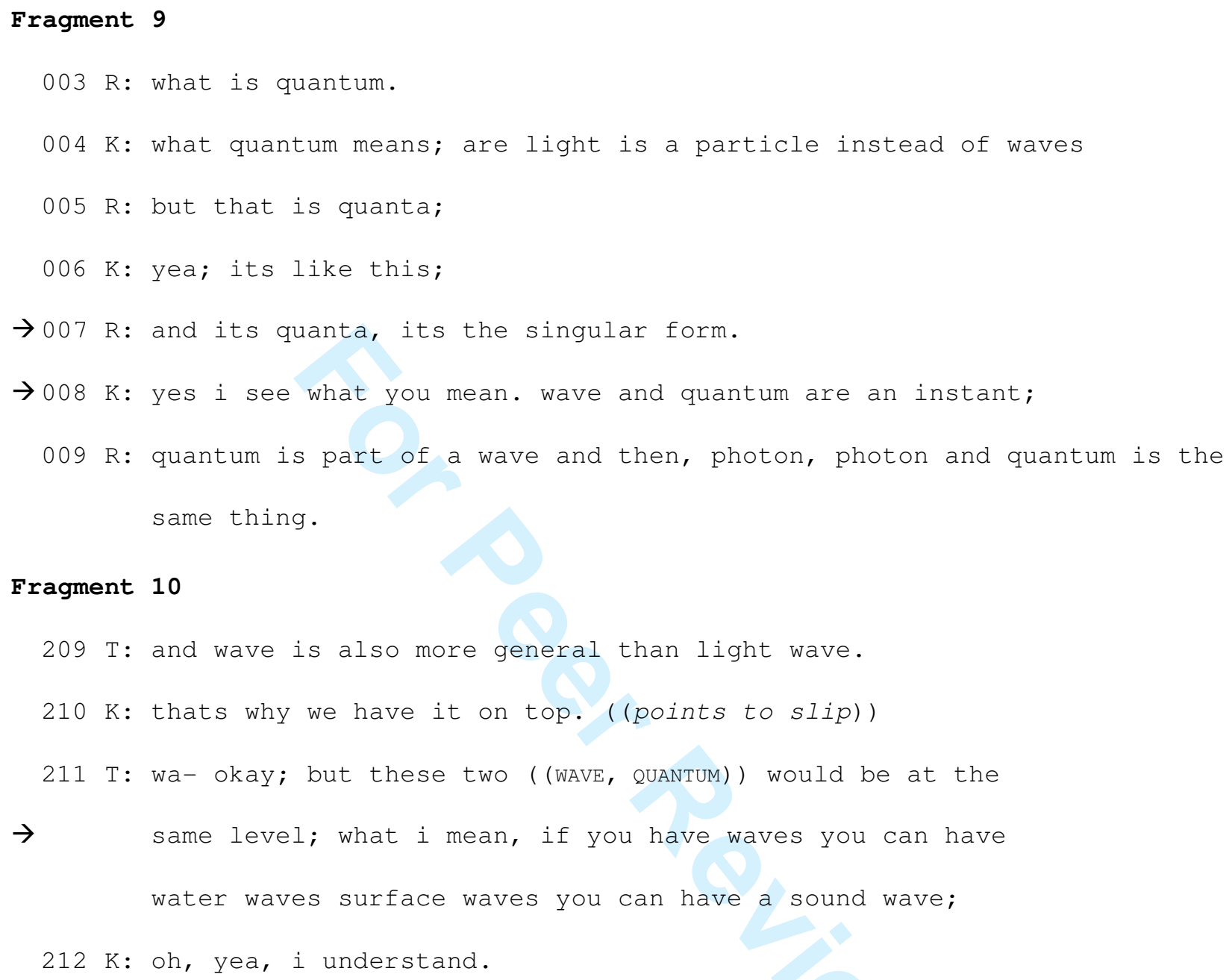

The same expression may be used in the question | question pair, where the second speaker asks what the first person meant. As a result, we then generally observe the first speaker use different words to say what is understood to be the same without using the same words. The result, however, will be that the listener now understands and the conversation may go on.

The data mobilized in this section exemplify language as a living phenomenon, continuously transforming itself when the speech of one speaker is taken up in the speech of subsequent speakers. Reported speech, in direct, indirect, and quasi-direct form together make up the central mechanism of the self-movement of language when it is used. It leads to the transformation in the statements that students make with specific words and phrases. In the next section, I present 
the evolution of the connections of the term complementarity in the course of one concept mapping session to exemplify the dynamic of situated language evolution that is, according to Vygotsky and Vološinov/Bakhtin, constitutive of language evolution on the ontogenetic and cultural-historical scales. The description, which emphasizes the turn pair, exemplifies a form of analysis that does not attribute speaking turns to individuals — which tends to be the case in current research (e.g., attributing conceptions to individuals) — thereby making it a static, monologic statement (Bakhtin, 1975).

\section{Continuous Evolution of Language-in-Use in a Concept-Mapping Session}

The second major insight on the part of Bakhtin/Vološinov and Vygotsky is the fact that any word, statement, and language undergo continuous change. Evidence provided elsewhere shows that the students had previously produced individual concept maps that were very different what they arrived at together; and the three participants differed little from what they arrived at together in 1- and 6-week delayed post-tests (Roth, 2009). That is, there is evidence that this lesson contributed to a change in the kinds of statements these three students subsequently made concerning the complementary character of light. Elsewhere I also shown how changes, which occur in real-time talk, lead to and reflect changes at the cultural-historical levels (Roth, 2010b, 2013a, in press-b; Roth, Lee, \& Boyer, 2008). (Space limitations prohibit such an analysis here.) What was not available at the time of previous research was a theory that embodies the language as a living phenomenon. To exhibit this phenomenon, I trace in this section the origin of all propositions in the final concept map that include COMPLEMENTARITY. As Figure 4 representing part of the students' final product shows, there are two pairs of such propositions. In the first pair, complementarity appears as part of the predicate that specify the subjects, LIGHT and XRAYS. The next pair of propositions include COMPLEMENTARITY in the subject position, which is specified by the predicates "may act as WAVE" and "may act as QUANTUM." As the following description and analysis show, the exact nature of these propositions remains open up until the final instant when these are inscribed on the sheet of paper that the students submitted. This 
submission constitutes the result of the students' irreducibly joint practical (i.e., "sympractical") work (Leont'ev, 1969/1971).

This result does not, however, represent the living work, which is available only in and through a first-time-through analysis of the unfolding relation. The unpredictability of the final outcome suggests evolution and emergence rather than "construction" as suitable nouns to denote the process. In this process, the nature of the relationship is open and unfinalized, as it would be in any truly dialogical relation (Bakhtin, 1929/1994). This is so even though the nature of the final configuration appears to be related to the interactions involving the teacher-especially the hierarchical relation between WAVE and QUANTUM and the parallel nature of their relation to the term COMPLEMENTARITY. Here, the collective thought is evolving without a final end in sight, an unfinalized dialogue that does not lead thought toward a unitary-i.e., monologic — whole (Bakhtin, 1929/1994; van Eijck \& Roth, 2011). Every thought is a rejoinder in an unfinalized dialogue, which here comes to an end only because of the institutional arrangement that makes lessons end according to the clock rather than because some "natural" end has been achieved. As the fragments presented here show, the students worked hurriedly in the end: in the apparent attempt to complete their concept-mapping task by the time the scheduled lesson ended. Each articulated thought, therefore, lives "a tense life," which is always at the border with someone else's consciousness. It is oriented to the event as an open-ended phenomenon. Given the fact that different student groups arrived at different propositions embodied in their concept maps, we may in fact concede that the de facto purpose was not to arrive at the same map in all groups, which would have meant that only one truth was acceptable in the class.

\section{««"«" Insert Figure 4 about here "I"।"।"}

In this sense, concept mapping allows the evolution of connections between words to form propositions and, therefore, extend or restrict the possible set of propositions that these form. But changes in the connections between words is equivalent to changes in discourse, which, here, were produced even though the students did not have the intention to change their discourse. That is, significations may be developed in the course of concept mapping sessions while 
students participate in developing an organized set of propositions in the form of the map. In this section, I focus on all of those fragments from the talk in one group of a concept mapping session that pertains to the emergence of a set of statements concerning the term complementarity (noun, adjective). That is, I exhibit the evolution of the talk from the instant when the three students first utter the word (or point to the piece of paper where it is inscribed) to the final statements that the student make with it as per the linkages between it and other words in their final concept map (Figure 4). This map will turn out to be very different from the ones that the three each had produced with the same words prior to the lesson (cf., Roth, 2009).

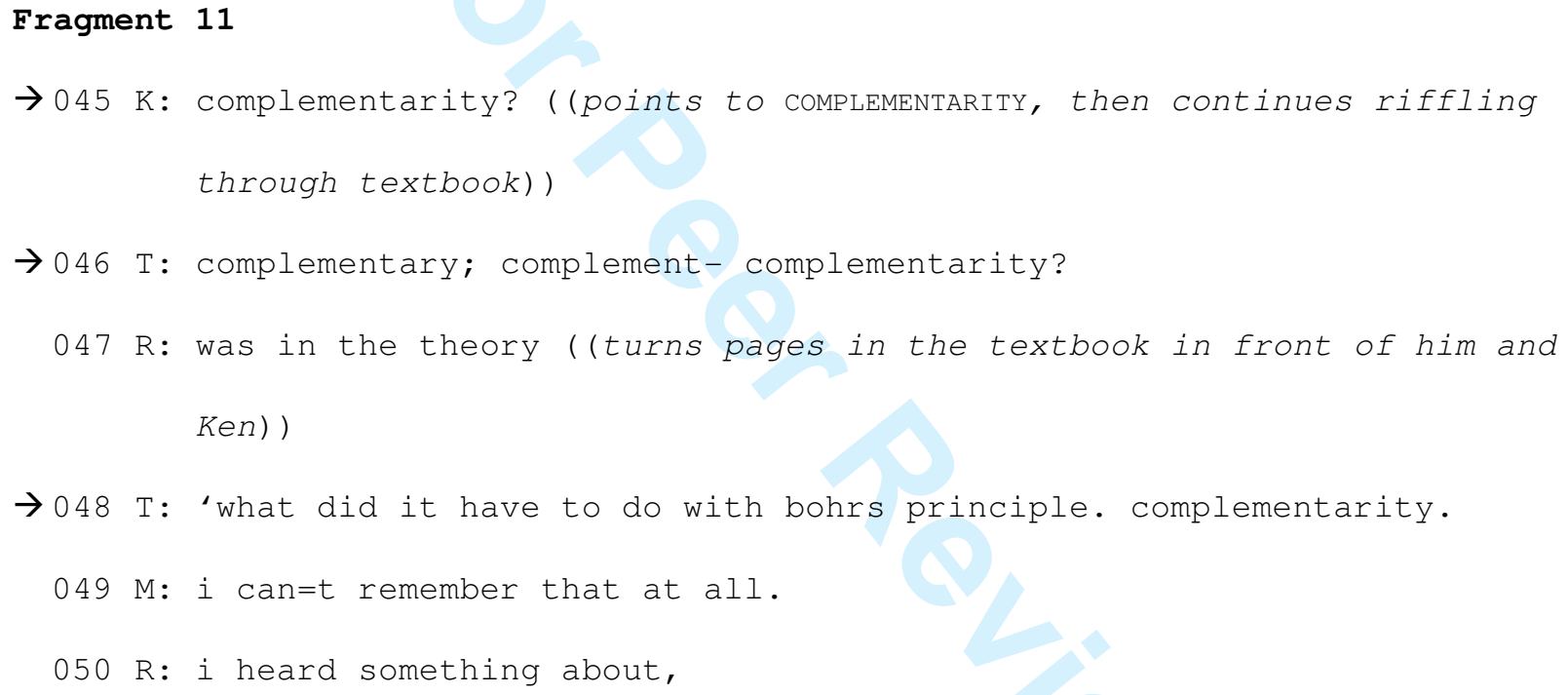

In Fragment 11, Ken apparently continues to look for the term in the textbook (turn 45), as he never had laid it aside since Fragment 1 when he had begun rifling through the pages. Similar to Fragment 1, the intonation co-articulated in the sound-word "complementarity," the inscription on a paper slip to which Ken also points, offers up a question. In the second part of the pair, the teacher articulates the adjectival form, then a fragment, and finally the sound-word with rising intonation. As in Fragment 1, the turn pair raises a question about the question. Here the second part of the turn might be heard as glossed by the phrase "So what about complementarity?" The next turn pair can be heard as a question-response, which attributes the term in question to some theory. We do not have complete evidence that this second turn takes up the preceding locution, 
so that it may not come as a surprise that the teacher returns to the issue of complementarity: "What did it have to do with Bohr's principle? Complementarity" (turn 48). In fact, this locution as a whole consists of two parts: the first has the grammatical structure of a question (even though intonationally it falls like a constative); the second part consists of a one-word constative statement: "Complementarity." The first part appears to offer something as a second turn in a question | reply sequence, to the question about complementarity. But there is a potential ambiguity, because the referent of the "it" maybe unclear given that the preceding locution may be heard as not having a connection with the theme. Thus, the statement "complementarity" provides this missing reference. However, whereas normally the pronoun would be used to a previously stated entity, it now precedes the noun that it specified. Whereas at a textual level it does indeed follow the antecedent "complementarity," and although its use lets the hearers know that something from the previous talk is being pointed to, pragmatically it solves the (potential) ambiguity in the precise nature of the referent.

This is actually an important aspect in support of the theory of language that Vološinov (1930) presents, for the second part of the locution makes previous speech an object of talk and reflects an attention to the needs of the audience. Thus, in this situation, the locution itself immediately resolves the potential ambiguity for the listener what the referent of the "it" may be; it does so by providing the response of the potential question that a listener might have about the contents of the message. It is part of the classic construction of a paragraph, which immediately addresses inherent features of speech such as apparent contradictions and absurdities, stumbles, pauses, malapropisms, mumbles, ingrammaticisms, and the likes.

Here we observe development, the second part of the locution in response to an issue that the articulation of the first part generated. It is these generative aspects that characterize speech activity (language-in-use, Fr. langage). The pair consisting of turns 48 and 49 can be heard again as question-response, where second turn is also a statement about not remembering what the term under question, complementarity, have to do with Bohr's principle. The form of the locution does not say that the student did not remember Bohr's principle or complementarity but 
rather that he does not remember the connection between the two. Turn 50 can be heard as the second response to the same question, a statement that the speaker has heard something about. It also sets up a contrast with the immediately preceding locution, an assertion and a counterassertion, or second assertion that presents a different matter of affairs. The next turn is a non sequitur, introducing a new topic that has no direct antecedent but that is taken up in the next turn. The turn sequence therefore offers and accepts a change of topic.

The next time the teacher comes to the group on his round during which he checks with all other groups on their progress, there is a first question-response turn sequence about the term “complementarity." Listening in on the exchange in Fragment 12, we find out that there apparently has not been much progress: "the term is not even in the index" (turn 71). The teacher stays with the group and an interaction unfolds that apparently has complementarity as its topic (Fragment 7). Miles takes up the offered question about the content of the last chapter is taken up in the subsequent turn and, when there is another question offered about the content of the preceding chapter, it is taken up in the response that offers the "duality of wave" as a reply. The evaluative turn consisting of the one-word locution "exactly" completes a familiar three turn IRE sequence in which a teacher takes the first position that initiates the sequence, a student replies, and the teacher produces an evaluative statement (e.g., Alonzo, Kobarg, \& Seidel, 2012; Lehesvuori, Viri, Rasku-Puttonen, Moate, \& Helaakoski, 2013). But there is more to it, as the student's acceptance of a question through the provision of an answer already constitutes a social evaluation (Vološinov, 1930). It is this uptake that allows the lesson to unfold in the way one might expect for schools serving middle and upper-class populations (as here in an expensive private school), but which may not be the case in other school settings where (class) conflict is playing out on a more regular basis (Roth \& Tobin, 2010).

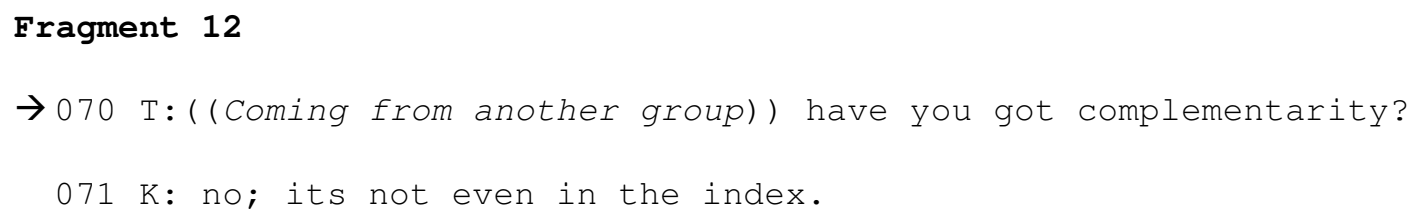




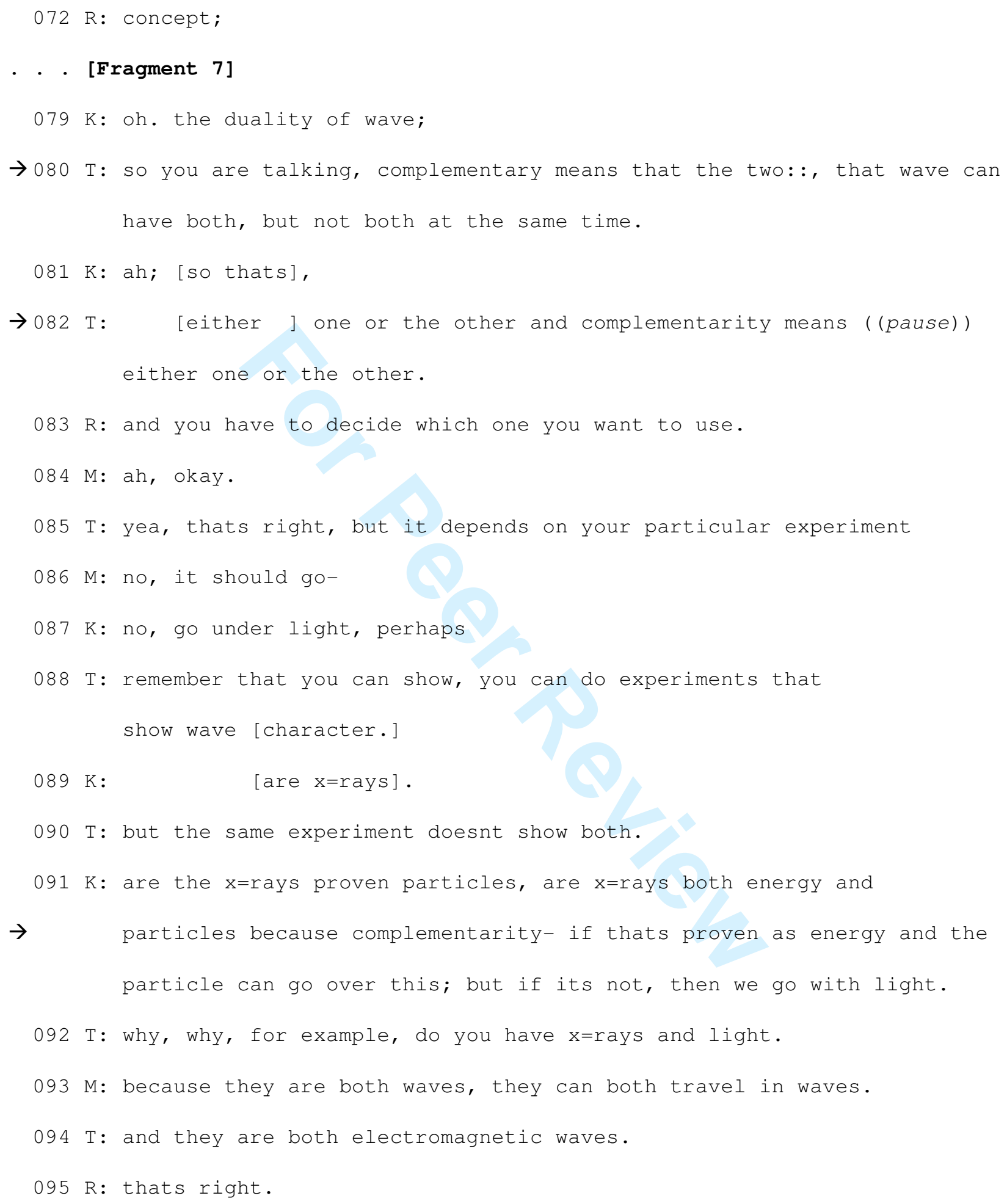

In turn 79 , we also observe something like an evaluative turn, which begins with an interjection that tends to mark surprise "oh"; here it is followed by a repetition of the last part of 
turn 77. In this repeated version, however, the sense/theme of the word is not exactly the same, not in the least because it is uttered against a background part of which includes the original. The function of the second occurrence is different, which changes its sense/theme (Vološinov, 1930; Vygotskij, 2005). We may gloss a likely hearing as "Oh, yea, this is right, it was the duality of wave." The thematic of duality is taken up in the next, the teacher's locution (turn 83), which further develops the theme and, therefore, also positively evaluates what has been said before by accepting it as the basis on which the further development occurs. There is a student attempt at taking the speaking floor, which is overlaid by the teacher's talk, which in fact constitutes a grammatical completion of his earlier turn. It has summarizing quality: "Complementarity means either one or the other" (turn 82). The next student turn then builds on this one offering an elaboration of the "one or the other": "You have to decide which one to use." In saying "ah, okay," Miles' locution not only acknowledges what has been said but also offers up an indication of understanding the content of the preceding explication. The teacher's turn produces two positive evaluative markers: "yea" and "that's right" (turn 85). But then it continues using the contrastive connective "but," which in fact offers a delimitation of what has been said. It is right, but in a restricted sense that "it" depends on your experiment. The next two student-produced locutions already appear to indicate that they are continuing, and thereby also mark that the topic has been completed. The teacher's locution, however, picks up on the experiment, the concept word that connects the three locutions he produces: turns 85,88 , and 90 . In the final one, he takes up again an idea already articulated in locution 80 , which connects complementarity with having both (aspects) of the duality.

In Ken's turn, which is longer than any other up to this point, $\mathrm{x}$-rays are introduced together with the concept-words "articles," "energy," and "complementarity." The statement offers an alternative. If the X-rays have particle character, then the paper slip PARTICLE can be moved above that of light and X-rays; if not, then LIGHT should appear above the other (turn 91). The next turn, produced by the teacher, takes up the words x-rays and lights. The turn, although articulated with the falling intonation typical of constative statements has, beginning with an 
interrogative, the grammatical structure of a question. It functions as a question, because the next turn provides, in a constative form, a statement about "both" phenomena: "they can both travel in waves" (turn 93). In his turn, the teacher's turn uses both terms but adds "electromagnetic" to what is a repetition of the first part of preceding locution: "and they are both electromagnetic waves." As the falling intonation marked by the period at the end of the transcribed locution suggests, the statement is offered as a constative. It takes up and repeats almost identically a part of the preceding locution in a constative form, thereby marking agreement and positive evaluation. In not taking up the second formulation ("they can both travel in waves"), it thereby lends support to the first of the two offered formulations that appear in the preceding locution. Ralf produces a confirmation "that's right," which would have functioned as an evaluation if it had been the third position of the IRE sequence, which in fact has already ended in turn 94.

In this part, we observe that the third position in a teacher-student-teacher turn sequence is not just evaluating but there is a movement from the first to the third. The second, student turn, in taking up, responding to, and thereby completing a question-answer pair when followed by a positive evaluation has covered grounds for continuing, itself as movement; on the other hand, a negative evaluation also will lead to a continuation of the lesson but with a retarding movement, a back eddy designed to prepare the grounds for the larger movement to continue. That is, a negative evaluation or restriction of what has been said before, as in turn 85 , also constitutes movement but not in the same direction as when there is a positive evaluation. In the former case, some already covered ground comes to be repeated, whereas in the latter case, the conversation tends to begin covering new ground.

Fragment 13 occurs not long after the last fragment, the sound-word "complementarity" appears again in a proposition that relates it to light, on the one hand, and wave and matter, on the other (turn 115). The next turn, in placing MATTER WAVE below WAVE, not only proposes subordinating the former to the latter but also accepts and reaffirms its hierarchical position. In that turn sequence the hierarchical order of WAVE above LIGHT is reaffirmed. The next turn, however, already overlapping the one just coming to a close, offers a different, alternative 
hierarchical ordering together with the (rejected) physical move of the paper slip imprinted with LIGHT to the top position (turn 117). This discursive and practical move, therefore, constitutes a change to what has been, and, therefore, a challenge to the status quo just affirmed by the two other members of the group. In the next turn, however, a reversal is brought about, discursively and physically, by moving the paper slip back into its original position, placing LIGHT below WAVE. The trajectory of the conversation, therefore, moves through affirmation, reaffirmation, challenge, and reaffirmation of a particular hierarchical ordering that places WAVE on top of the hierarchy and LIGHT, MATTER WAVE, and the term in question, COMPLEMENTARITY, below it. It has been suggested that these processes of affirmation, challenge, and (repeated) reaffirmation underlie the evolution of language and the convergence to new linguistic forms that change more slowly (Rorty, 1989; Roth, 2005).

\section{Fragment 13}

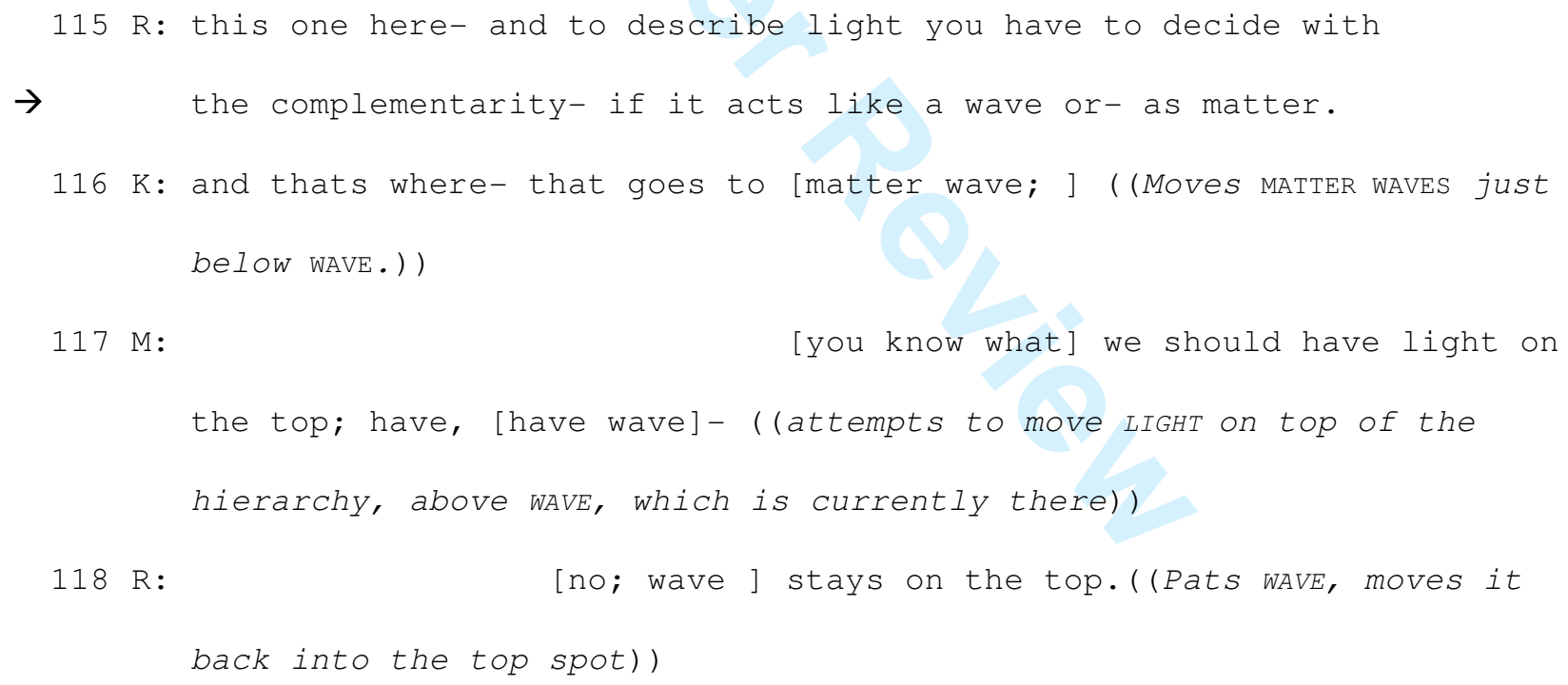

The talk continues to evolve, producing new statements and relations between the concepts. Thus, in Fragment 14, complementarity comes to be linked to Planck's constant, which is to be subordinated to the former, currently very high in the hierarchical order of paper slips. In the turn pair 135/136, complementarity is related to kinetic energy, defined, in the statement, as Planck's constant (h) times frequency (f), and to something else, which never comes to be fully 
articulated. Turn 136 appeals to authority and authoritative discourse (Bakhtin, 1975), as the speaker refers to the textbook where a statement can be found that would substantiate what might be heard as the claim that "it's connected." Appeal to authoritative discourse is part of a transitional movement to speaking competence and internally persuasive discourse (Hsu \& Roth, 2012).

Fragment 14

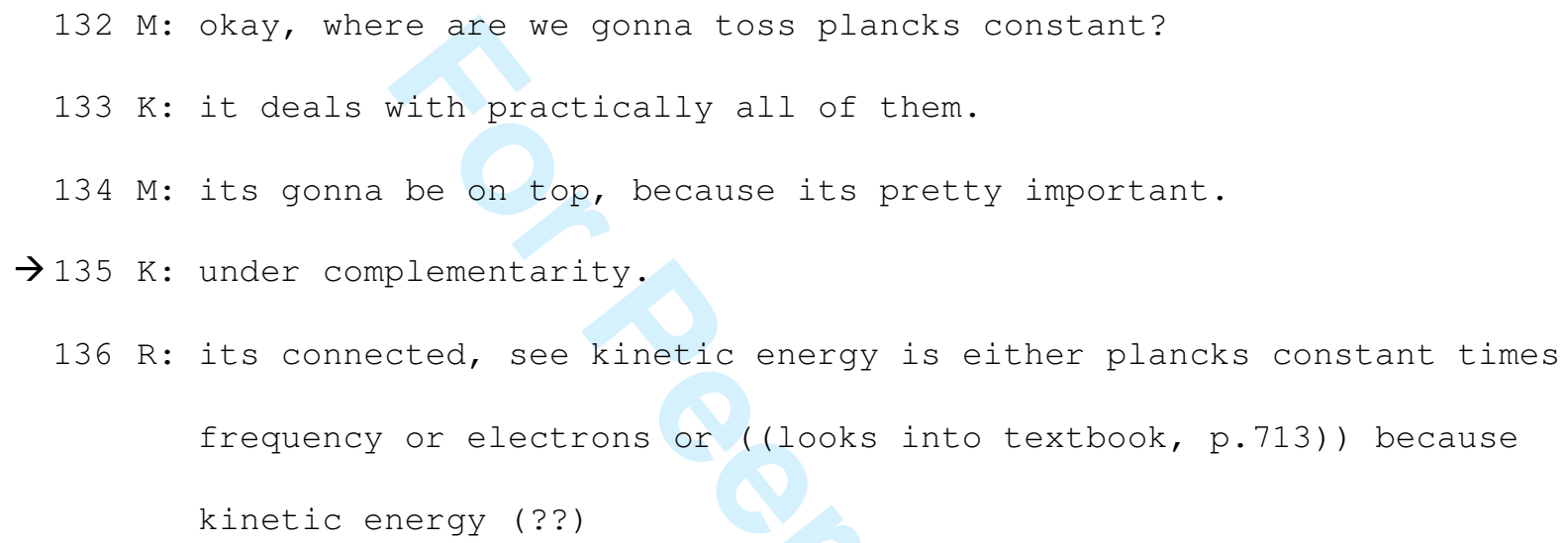

Three full turn pairs constitute Fragment 15. In the first pair (turn 139/140), there is a question-reply concerning the placement of MATTER WAVES and the statement of an example of a matter wave when an electron travels. In the second turn pair, there is a negation ("no") followed by an acceptance and a statement about understanding (the concept) and then a proposal that "it" (MATTER WAVES) would be placed below COMPLEMENTARITY. There is also the beginning of an offer of a reason for the placement "because that's like quantum?" (turn 141). We can hear the locution as an offer, because, rather than constituting a statement, which would be indicated by a dropping intonation, the latter rises so that we can hear the phrase as a question. In the context of the next locution (turn 142), which constitutes the social evaluation (Vološinov, 1930), there is a rejection, though, at this point, we do not know whether the placement or the explanation is concerned. The second part of the locution provides a statement about "that guy's wavelength," which we can hear as a reference to the de Broglie wavelength that attributes to matter with a momentum $p$-the product of multiplying the mass of a particle $\mathrm{m}$ and its velocity $v$, i.e., $p=$ 
$\mathrm{m} \cdot v$ - a wavelength $(\lambda)$ according to the equation $\lambda=\mathrm{h} / p$, where $\mathrm{h}$ is Planck's constant. In this fragment, we find two negations. If these were absolute negations within a single statement of a single subject (e.g., in a student's science writing), no development could arise; but as negations between different subjects and statements, they give rise to dialogical relationships and associated evolution of language and ideas (Bakhtin, 1994).

Fragment 15

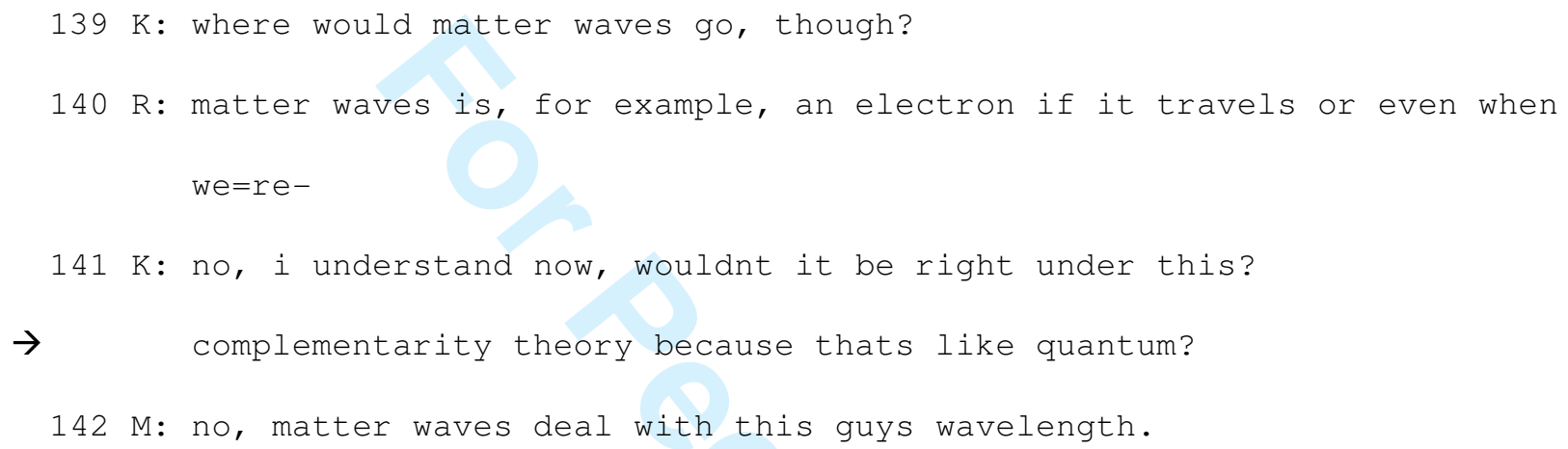

In Fragment 16, which arises out of Fragment 5, the teacher is present again. The articulation of "complementarity" arises from an exchange over the term quantum. Subsequent to the teacher's locution that brings the parallel nature of wave and quantum back into play, followed by at least one student turn that takes the parallel up, there are several turns none of which reaches the state of full proposition. There is a partial statement intonated such that it can be heard as a question: "aren't they like two different ..." (turn 162). Its uptake is very clear, because it explicitly articulates having heard the teacher saying something other than he has said in the precise words. It constitutes an uptake and transformation of what the teacher has been heard to say: "that they should pop light on top and have complementarity," leaving open where COMPLEMENTARITY was to be placed. In the next turn, the teacher actually rejects the description of what he was said to have said and formulates that he is "just asking [a question]" (turn 164). The nature of X-rays comes to be raised, out of which another relation to complementarity is being articulated. Spread across the turns 170 and 172, there is a proposal that students "may want to change" and, without a grammatical connective term, suggests that WAVE and QUANTUM 
have complementary character. This is taken up in transformed form in the statement that the terms "should be at the same level." This proposal is de facto accepted in the locution "they would be at the same level," which is intonated as a constative and, therefore, as a matter of fact. In this fragment, therefore, we see repeated uptakes and therefore transformations. Because uptakes hybridize the voices of two subjects, there is therefore inherent development rather than stasis (Roth, 2008a; Vološinov, 1930). That is, uptake and reaffirmation constitutes evolution rather than constituting mere repetition because it leads to statements in which the voices of different speakers can be heard simultaneously.

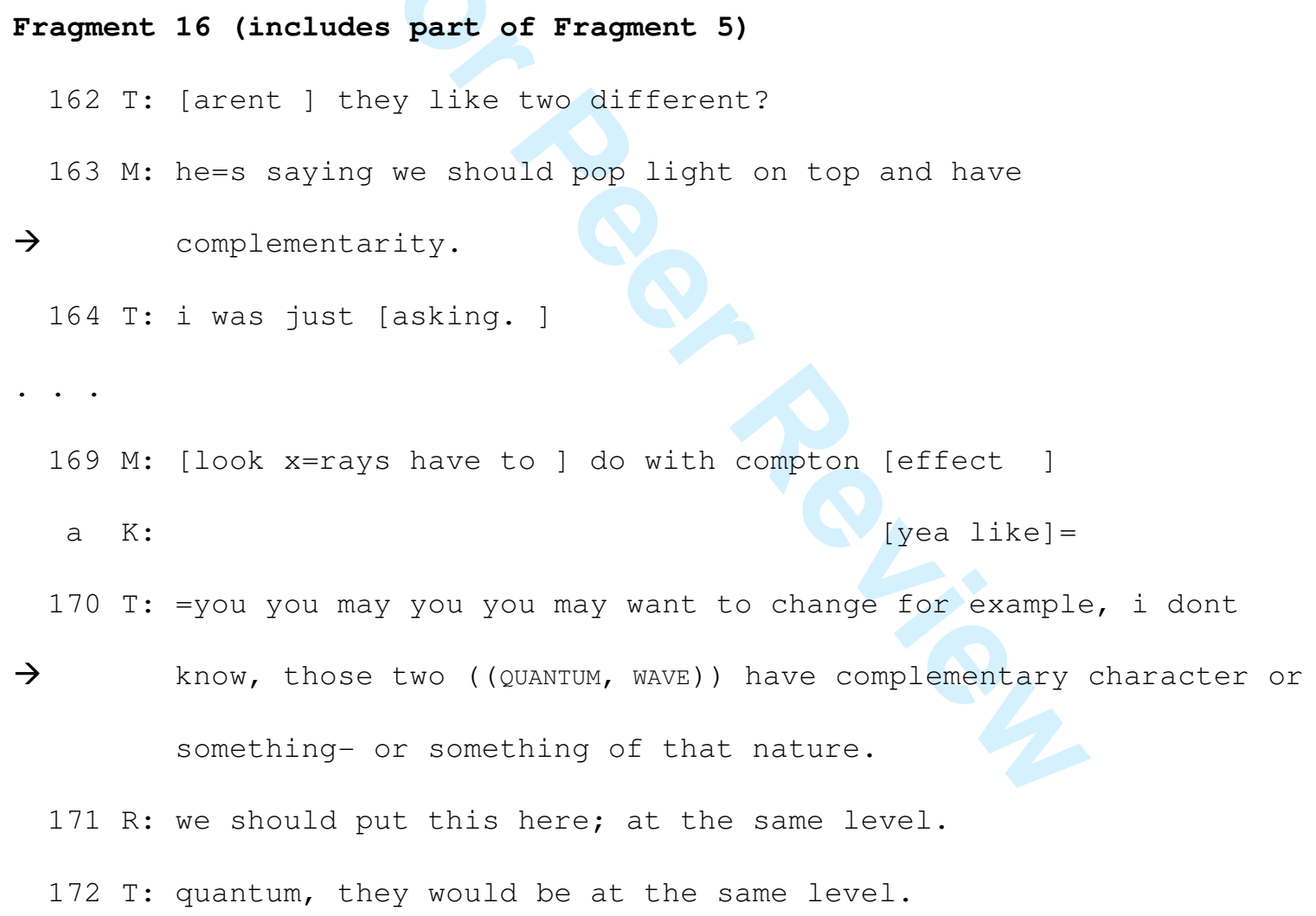

It is in the exchange of Fragment 17, an extension of Fragment 8, that movement can be observed toward considering wave and particle character at the same level and their "equal status" (turn 241) as a result of the "complementarity principles" (turn 240). The fragment begins when there is a tentative proposal to place COMPLEMENTARITY across several other terms currently at the top of the hierarchy. All three burst out in laughter and, thereby, constitute this 
potentially tentative proposal as a joke while underlining the seriousness of their endeavor (Roth et al., 2011). Laughter is inherently ambivalent because it marks the presence of different ideas, the birth of one and death of another; and, in doing so laughter marks the movement of life itself (Bakhtin, 1994). In the conversation, such a move of the concept word clearly would have broken the rules of engagement, which requires the concept words to have a place in the hierarchy and connected to other terms by means of linking words to be created - rather than taking the concept words and turning them into linking words. The statement that COMPLEMENTARITY "has to go somewhere" (turn 236b) follows. In fact, one might hear the statement also as a question of where in the hierarchy the concept word should go. The second part of the turn pair begins with a statement about having liked "it," followed by a reason, according to which wave could then moved further downward in the hierarchy from the current top position it has.

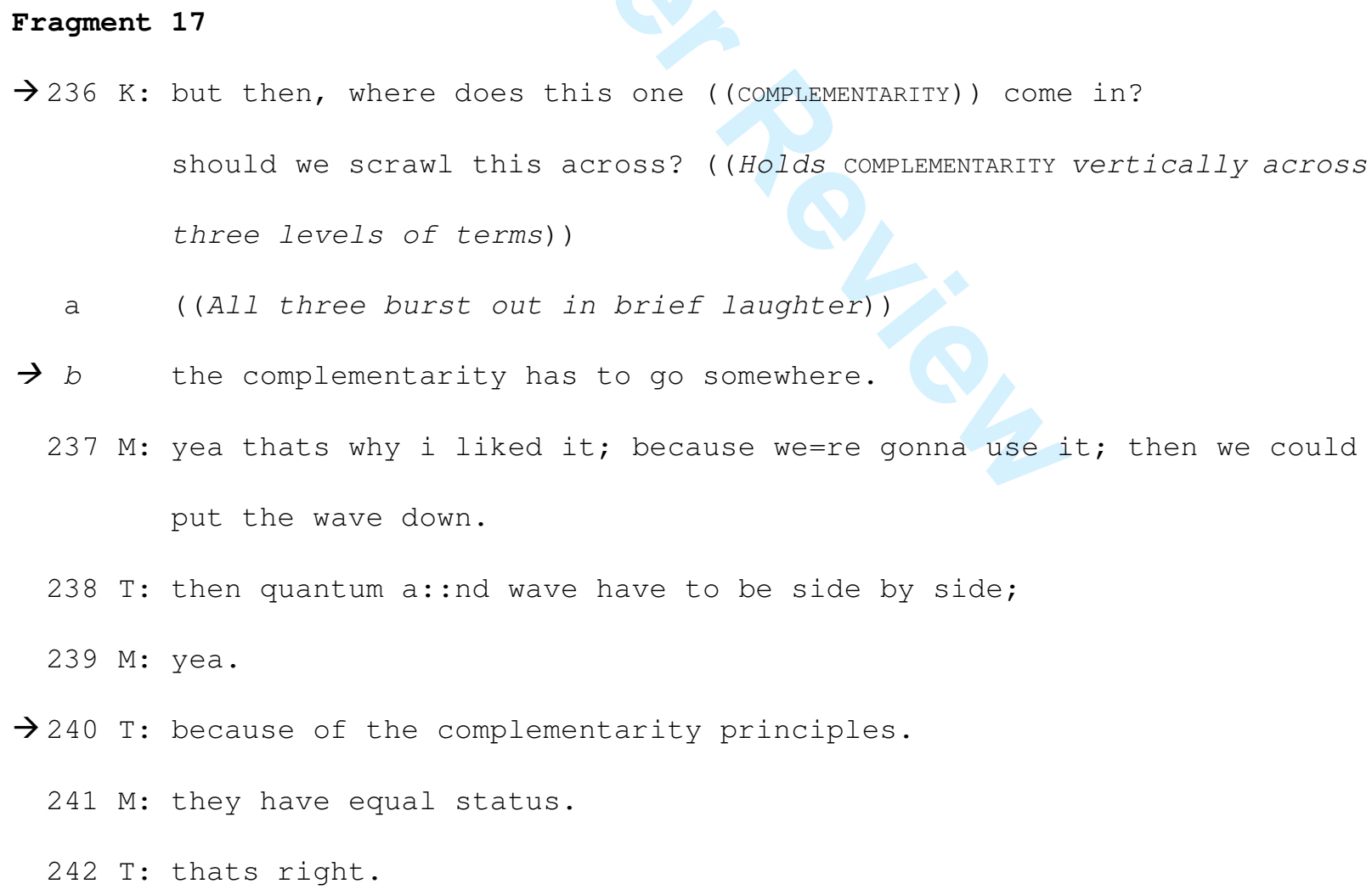

The teacher takes the next turn with a statement that makes an implication: "then quantum 
and wave have to be side by side," which, following a statement of acceptance ("yea") is further elaborated by a reason: "because of the complementarity principles" (turn 240). The pair 240/241 produces a statement and its elaboration: because of the complementarity principle, the two terms, wave and quantum, "have equal status." In the next turn, the teacher utters an acceptance and evaluation ("that's right"), which might be heard as an indication of correctness with respect to his understanding of standard physics. There is an evaluative locution in the teacher's turn ("that's right") similar to the evaluations we might find as the third part of an IRE routine (e.g., Poole, 1994). However, in this situation the initiation turn arises in reply to a student assertion. This turn offers a reason for a particular case — wave and quantum side by side — rather than constituting the elicitation of a specific student reply. Providing reasons occurs as part of argumentation, an integral part of all authentic dialogue (Bakhtin, 1994).

Although turns 238, 240, and 243 might be heard as coming from a single authoritative voice, in which case it would have been taken up by others (Bakhtin, 1994), the conversation continues to offer up alternative relations between the concepts. The next time the term enters into the verbal exchange is immediately after an exchange involving Ralf, Ken, and the teacher, who had introduced phonons - i.e., quantized waves in a solid - as another example of a quantized phenomenon (Fragment 18). Miles has a longer turn at talk, in which complementarity comes to be articulated as the major concern in this concept map. The locution makes a statement that it could be high up in the hierarchy, without necessarily being needed, a question where it would otherwise be placed, and the consequences when the students "get down here" to the lower parts of the emergent map. The next turn suggest that what was heard is a proposal of having the same term appear twice and at different levels, which would result in "skipping levels with the same concept" (turn 257).

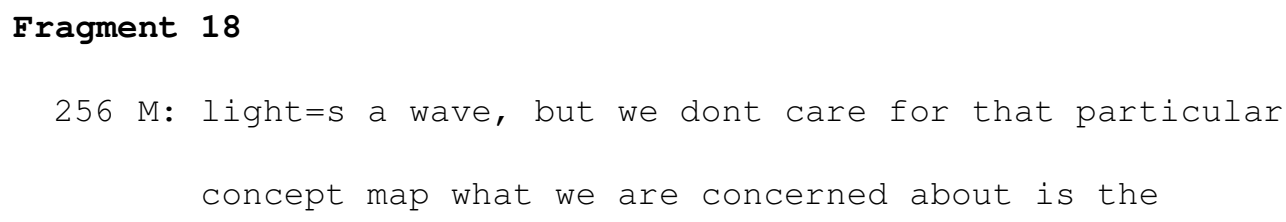




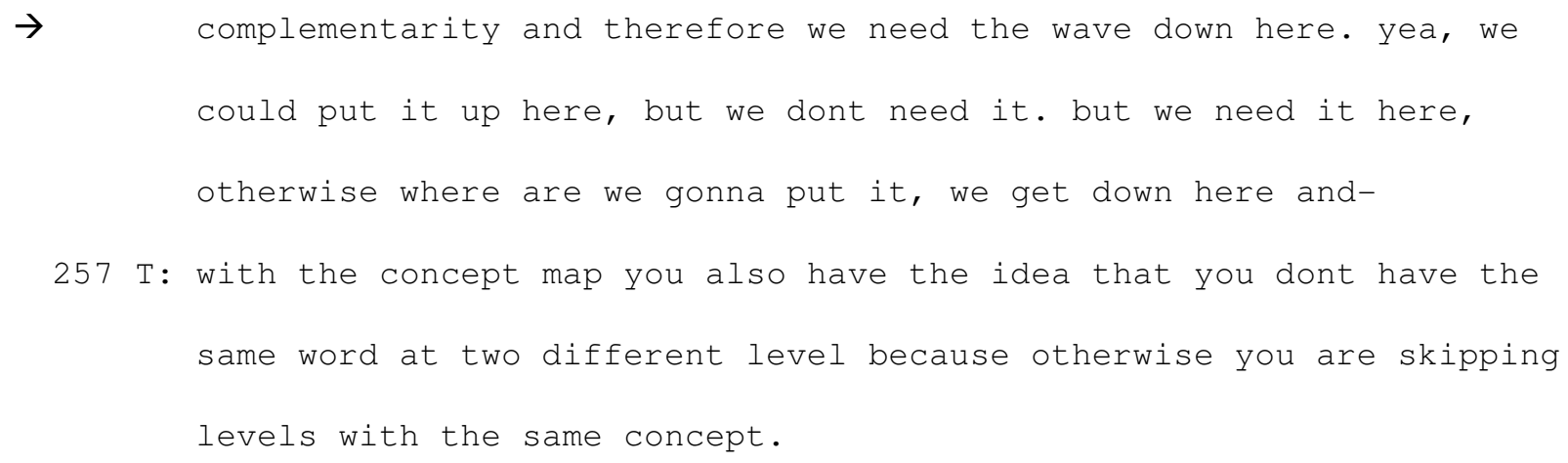

A little later, the question of where COMPLEMENTARITY should be placed still is not settled apparently. The problem is acknowledged and accepted as a problem by the next turn (turn 270), followed by, as per its uptake in turn 273, a proposal to place the term "under waves" (turn 272). The statement is made up of several statements that form an argument that because WAVE could go in several places, it does not need to have to be at one particular spot. Whereas Ralf's turns are associated with proposals of placing WAVE at the top, the present turn includes a statement about being left with half of something, which, in the present case, possibly is the other half of the "equal status" (turn 241) of wave and particle. There is acceptance, support, and further elaboration of the position in the next turn, which articulates again the wave and quantum nature of light, each being "just a detailed explicit expression of light waves and X-rays” (turn 274). Acceptance, support, and elaboration all are part of the interactive but momentary stabilization of forms of talk and individual speech capability (Roth, 2005). The latter part of this turn is taken up in the next turn at talk, attributing wave character to both (light, X-rays) and a proposal to leave the current state (LIGHT and X-RAYS above WAVE and QUANTUM) the two levels separated by the level containing only COMPLEMENTARITY (turn 275).

Fragment 19

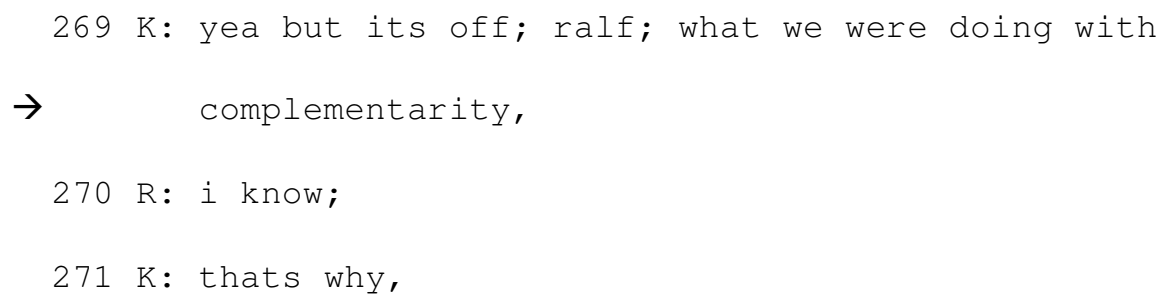




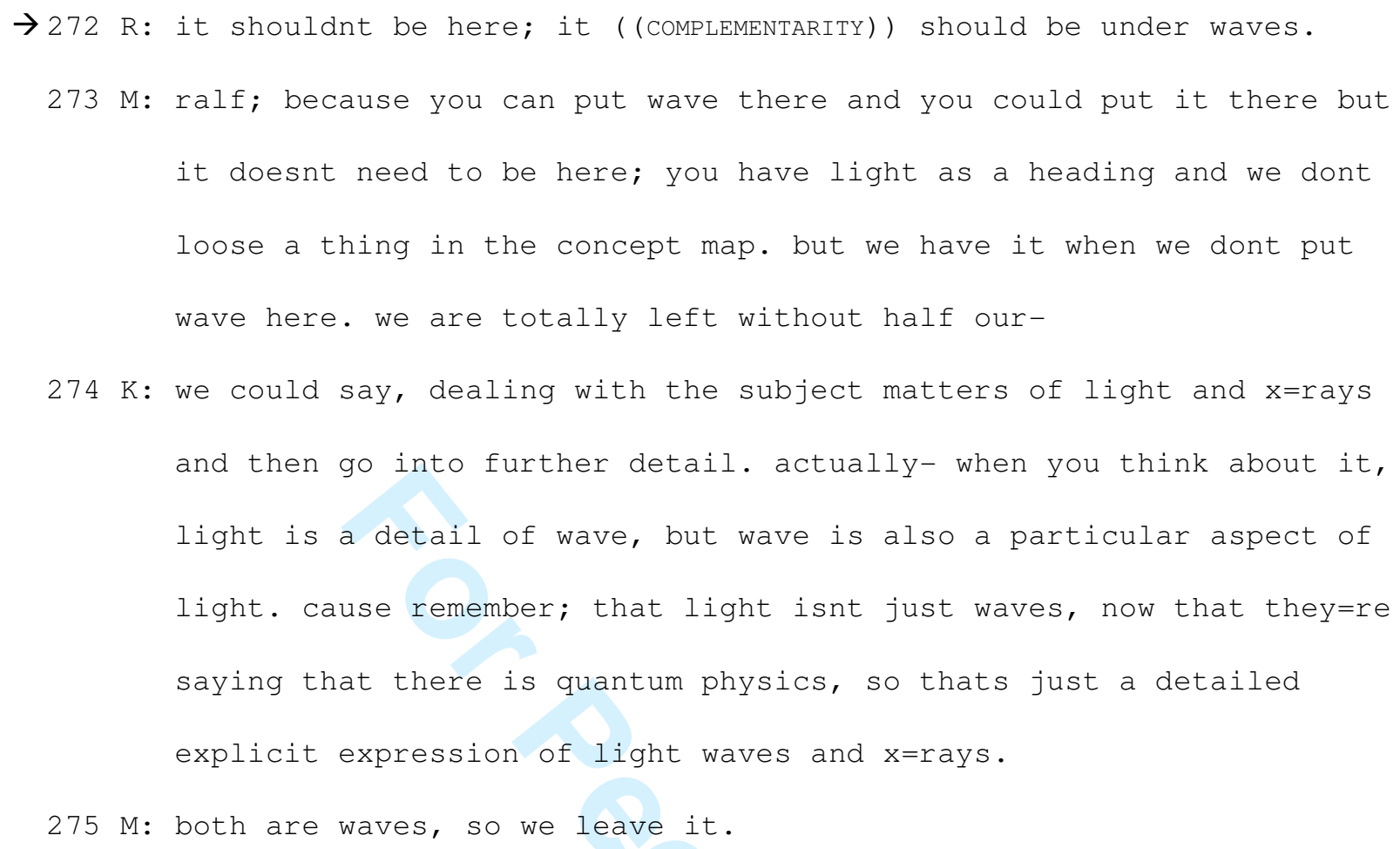

The final two appearances of the word in the talk occur during the transcription of the map onto a large sheet of paper (Fragments $20 \& 21$ ). That is, the task itself embodies the need for finalization of language evolution, at least one that is temporary. Elsewhere evidence is provided that at least the concept maps that the three produced individually thereafter, at least in some of their central aspects, varied relative little from what they had done together but varied a lot from what they had done individually prior to this session (Roth, 2009). In the following two fragments, therefore, we can observe indications of the living work by means of which a long debate comes to conclusion. Fragment 20 begins with the offer of a tentative proposal (again, there is a rising intonation in the first part of the locution and a statement in the second) about the placement of COMPLEMENTARITY above that of WAVE and QUANTUM (turn 398) and the acceptance of the placement and the side-by-side placement of COMPLEMENTARITY.

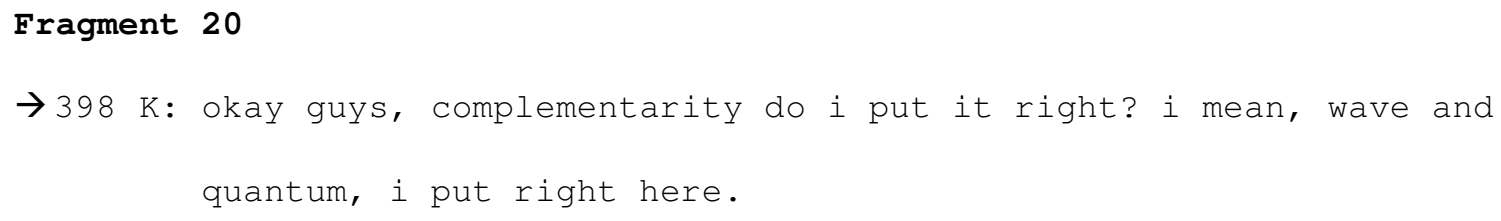




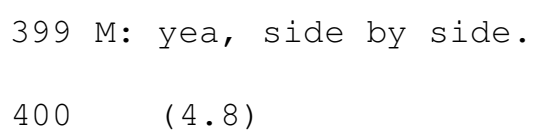

The last fragment pertaining to complementarity begins with an invitation to make connections "them all" and to find the words (that are to be written on the links). Ken's hand lies near the top of the hierarchy, where the words LIGHT and X-RAYS are found. This allows us to hear the next locution as a proposal for the linking term between these terms and the one below: COMPLEMENTARITY. The verb "possesses" is proposed; but the next turn, with an articulation that may be heard as expressing impatience, makes a statement about the sense in which complementarity is to be understood: "you just have to decide which one is useful" (turn 440). There is another proposal for placing "have" such that the propositions LIGHT/X-RAYS have COMPLEMENTARITY would result. The recording does not allow us to hear how the proposal is being taken up in the next turn, but it is followed by another verb articulated with rising intonation, which therefore can be heard as a tentative offer (a suitable gloss would be, "should we put 'have' here?") of placing "have" on the two pertinent links. The proposal is accepted in the next turn ("sure," turn 444) and thereby affirmed - an integral aspect of interactive stabilization of language (Roth, 2005).

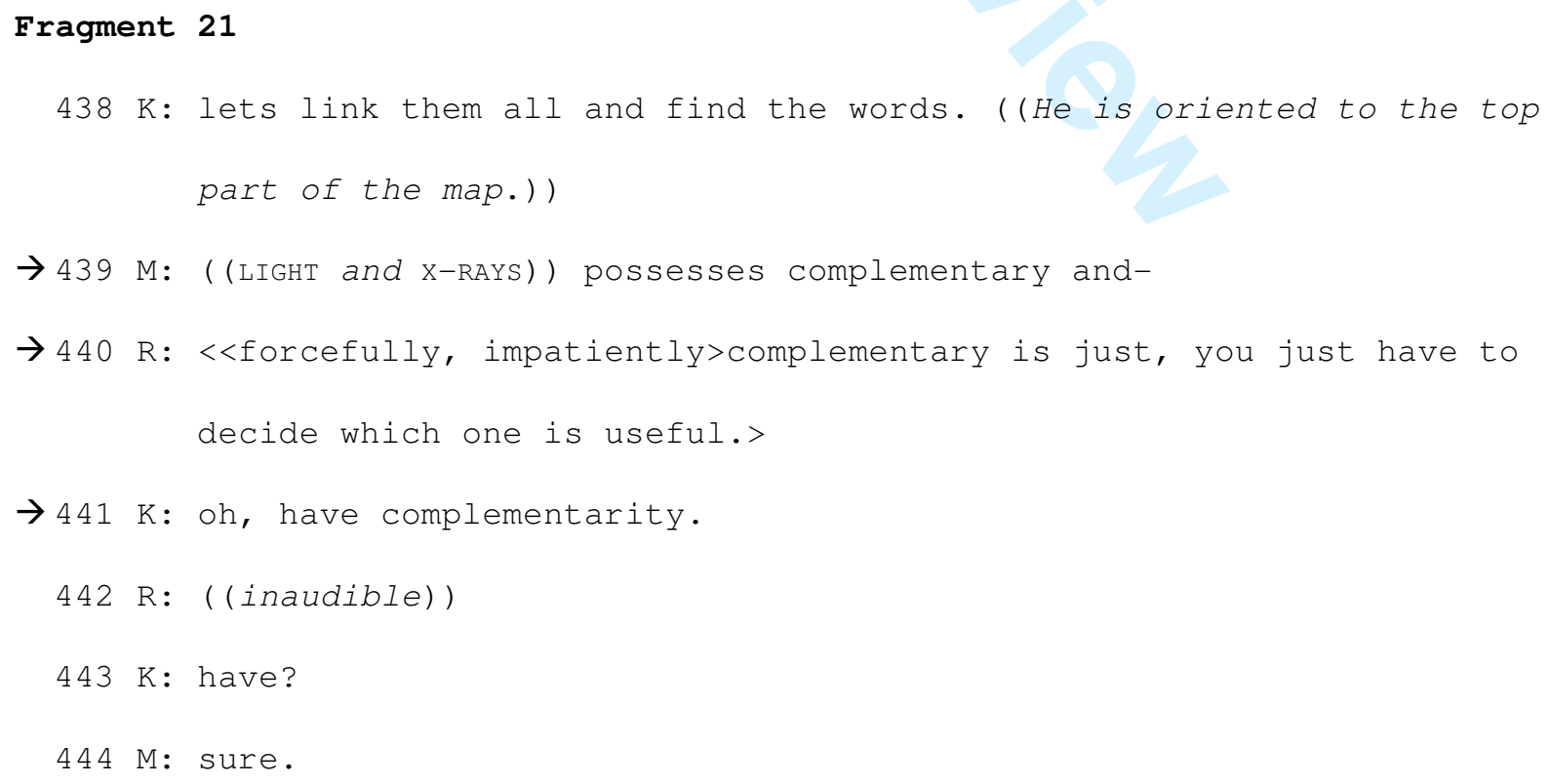




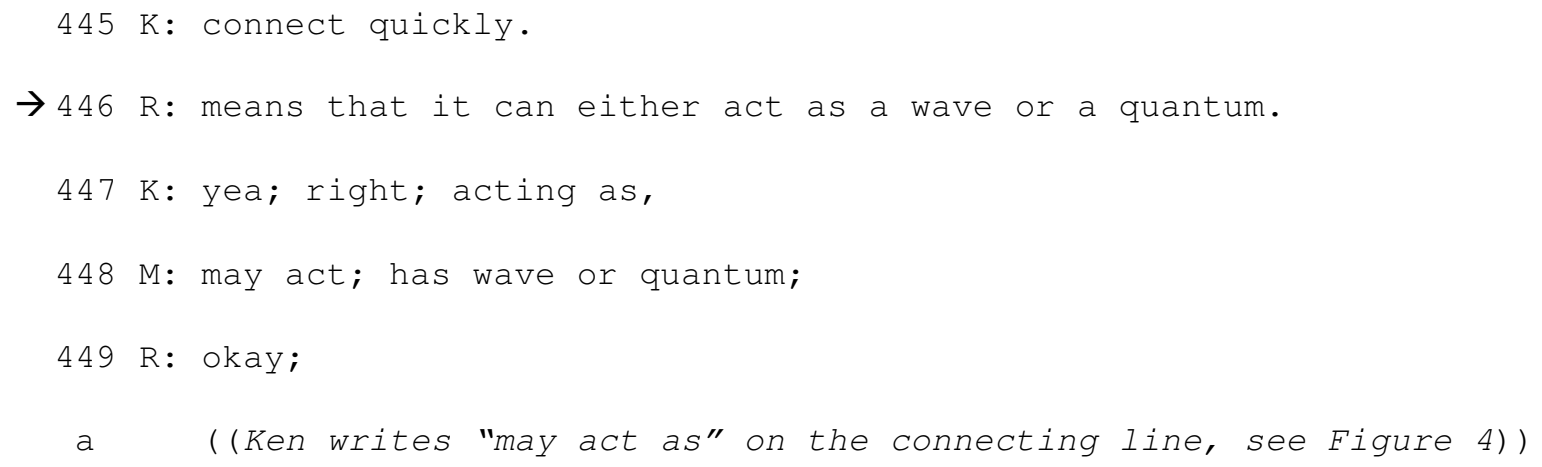

Although there might be acceptance turns, authentically dialogical talk always is unfinished (Bakhtin, 1994). This is also evident in Fragment 21, where further modifications are proposed to what appear to have been already accepted statements, matters of fact. The second part of Fragment 21 concerns the connection of COMPLEMENTARITY to the two terms that appear below it: WAVE and QUANTUM. There is a proposal-acceptance pair concerning the propositions COMPLEMENTARITY can either act as WAVE or QUANTUM are to be formed (turns 446/447). However, the acceptance ("yea, right") is followed by a modification (and therefore development) to replace the "either ... or ..." formulation by the verb "acting as." This can be heard as another proposal, which now stands side by side with the preceding one. In the next locution, which also constitutes an acceptance of the preceding one or ones with a slight modification offered to "may act," there is also another proposal to produce the configuration “[COMPLEMENTARITY] has WAVE or QUANTUM." This proposal is accepted in its corresponding partner turn. In fact, subsequent to the first proposal, we actually may hear proposal/counterproposal pairs without simultaneous rejection of the preceding proposal. Movement here is constituted by an expansion of available options. Fragment 21 ends with an assent-expressing interjection "okay" with (slightly) falling intonation, which can be heard as an affirmation. Ken writes "may act as" on the line connecting COMPLEMENTARITY to both WAVE and QUANTUM, thereby constituting a second acceptance turn and agreement of all three.

\section{Discussion and Implications}

The purpose of this paper is to articulate and exemplify an approach to language that 
emphasizes its character as a living phenomenon - rather than as a phenomenon with static (dictionary) significations and static grammar, which kills science language rather than keeping it alive (Richardson-Bruna et al., 2007). The first of the two exemplifying sections exhibits one of the central mechanisms by means of which language changes: direct, indirect, and quasi-direct (reported) speech, which is a consequence of the first major insight on the part of Bakhtin/ Vološinov and Vygotsky and component of the theory. The second of the two sections exemplifies the second major insight on the part of Bakhtin/Vološinov and Vygotsky and component of the theory: how language-in-use undergoes continued transformation from the beginning of the concept mapping session to its end in the course of which the scientific terms “complementarity," "quantum," "wave," "light," and "X-rays" find their place. Language change, the production of the map, and the statements that link pairs of terms irreducibly are intertwined: speech activity is an integral, constitutive part of the (concept mapping) activity as a whole (i.e., the language game in play).

This paper advances science education scholarship in two correlated ways. First, I propose a theoretical framework, captured in Figure 1, in which two movements along the orthogonal psychological and sociological dimensions constitute the continual change of language that occurs in and through irreducibly joint-practical i.e., sympractical) speech situations. This theoretical framework brings together-and thereby goes beyond-foci that appeared in the different frameworks of the sociologically oriented Bakhtin group and the psychologically oriented Vygotsky. The figure also constitutes a unit of analysis that transcends the individual and embodies time (i.e., flow and change). Second - as a consequence of the unit of analysis - a word, statement, or language (a) never belongs to only one person and (b) always changes each time a word is said. The self-movement of life and language exists sociologically in the statement, that is, the movement of the same word from speaking to active receiving. As a psychological phenomenon, speaking is the outer part of a movement that begins with thinking, which articulates itself in externalization. Thinking exists in and as a dialogical relation: it is a dialogical relation and, as such, the genetic origin of any individual thought (Bakhtin, 1994; 
Vološinov, 1930; Vygotskij 2005). However, the fullest articulation only occurs in completely externalized speech: writing (Vygotskij, 2005). In the episode provided here, students arrive near this stage when they inscribe the results of their work on paper (e.g., Figure 4).

The position elaborated here has implications for one of the dominant theories in the field: conceptions and conceptual change (Treagust \& Duit, 2008). As evident in a quotation provided above, the individual as the holder of knowledge, consciousness, feelings, and beliefs - $\mathrm{a}$ common position in current science education (Kelly \& Sezen, 2010) — is an ideology incommensurable with the position that Vygotsky and Bakhtin/ Vološinov stated. Methodologically this means that talk, whether in classroom or interview situations, cannot be reduced to individual sand employed used to get at their conceptions, conceptual change, beliefs, attitudes, and feelings. Furthermore, talk cannot be used as the basis for deriving any state of knowledge, cognitive structure, belief, or feelings because the word, statement, and language continuously change. But, on the positive side, such a unit does reveal change because it is built into the minimum unit of analysis (Roth \& Jornet, 2013).

This position therefore constitutes a radical departure from current science education practice. Previous research already shows that the position taken by the Bakhtin circle is incommensurable with conceptual change and boundary crossing approaches (Hsu \& Roth, 2012). The case study surrounding the word "complementarity" exhibits the continuous evolution and change of language in the voices of the three students rather than sudden conceptual change within or across ontological categories (Chi, 1992) or a change in mental representations (e.g., McClary \& Talanquer, 2011). Precisely because language is living, new forms of talking science emerge without requiring a previously existing conception or mental representation (Roth, in press-b). Future research needs to be conducted to investigate whether the assumption that students have conceptual frameworks is indeed a requirement or whether it suffices to model students' talk about scientific phenomena as arising from the dialectical relation of speech ability and available language.

Writing in science is an important topic of research in science education (e.g., Knaggs \& 
Schneider, 2012; Lara-Alecio et al., 2012; Sampson \& Walker, 2012); and there are recommendations that a greater integration of reading and writing in science would be particularly beneficial for girls (e.g., Baker, 2013). Although there is recognition that both talking science and writing science are integral to learning science (e.g., Polman \& Hope, 2014; Richardson-Bruna \& Gomez, 2009), a theory about how talking science leads into writing science is much harder to get by. Indeed, as historians and philosophers of science point out, there is a mismatch between doing (talking) science and writing science (e.g., Schickore, 2008). The description and analysis exhibit features of language that are distinctive of talk but that do not appear in the written word: predicativity, intonation, temporality, and the co-presence of a statement and its negation. Vygotsky and the Bakhtin group have recognized and explicitly stated these features as constituting the radical difference between the two forms of communication (e.g., Vološinov, 1930; Vygotskij, 2005). Many literary and philosophical scholars have recognized the radical difference between (a) living speech, representing the unfinished nature of the saying, which occurs in unstated context (including the subject of the statement) and (b) writing, which has to explicitly articulate context (including the subject of the statement) and therefore represents the finished nature of the said (e.g., Levinas, 1971; Ricœur, 1986). The written word fundamentally changes cognition (e.g., Linell, 2006; Ong, 1982). Thus, without the written word, there would not be science (and mathematics) in the way we know it today (Husserl, 1939); and the changes in written texts and genres are the result of changes in oral language (Bakhtin, 1975). The presented position on language has implications for the relationship between speaking and writing science. If verbal speech and classroom talk emphasize predicativity and evaluative intonation, and, therefore, has tendencies toward inner speech, then we must ask about the value of classroom talk to the development of science as a written communicative form. In the case of concept mapping, a framework for a written text is evolved. But to yield a text that can stand on its own, much more writing would have to be done to elaborate all the context that a text requires to be able to stand on its own (Roth, 2010a). There are many questions to be answered through future research. What would be the resulting relation 
between classroom talk and science writing? Does such classroom talk support writing in science? What forms of support are required that would allow students to move from what they produce through verbal communication into written form? Concept mapping, in fact, may be one of such forms, because what initially exists only in verbal form-and, as the episode provided here shows, in very abbreviated, predicative expressions - has to be converted into a network of (simple) propositions. The latter exist in the form of an explicitly stated subject, generally the more overarching concept word, and a predicate, itself constructed from a linking word and another scientific concept word. If Bakhtin's work on the relation between different literary texts were to transfer to science classrooms, this would imply that the differences in writing samples from the same students would reflect developmental changes that occur in (inner, outer) dialogical exchanges. There is a need for future research that investigates the relationship between speech and writing in science classes.

The model presented in Figure 1 has methodological implications for doing research on language generally and on talk in science lessons specifically. Because the word, statement, or language is a sociological phenomenon sui generis, we need to analyze the production and reception of the word simultaneously. There are then advantages of analyzing turn pairs over individual locutions that do not tend to be realized in current science education research. First, researchers get at the inner dynamics of a conversation, because researchers describe the recipients' uptake of a locution by the members to the setting rather than imposing their own interpretations of individual locutions. Second, because the interest is in the internal dynamic of the unfolding classroom talk, central to the analysis is how interlocutors take up the talk of others. No outside information or reasons are therefore used on the part of the researcher to explain why something is said (Roth, 2013e). Third, the statement cannot be reduced to speaker or recipient - in the way researchers use excerpts from interviews or classroom talk and attribute them to individuals (e.g., Varelas et al., 2011). What is portrayed in talk-because of the ideological nature of language (Vološinov, 1930) — are not the ideas, thoughts, beliefs, or conceptions of individuals but cultural ideas, thoughts, and conceptions. Even more important, 
talk has to be theorized as irreducibly interwoven with activity (language game), including the making of teacher-student and student-student relations, dimensions not currently addressed in science education research on the function of language in science learning. Science educators may be interested in exploring, through further research, the effect this position has on what can be inferred from interviews if every word is taken as both shared and unfinished.

\section{Coda}

Shifting our theoretical talk so that it captures language alive requires a considerable effort. This is so because grasping (comprehending) something inherently arrests (stops) it and, as exemplified in the phenomenon of dead languages, actually kills language. The image I intend to evoke with the title "Science Language Wanted Alive" is that of arresting something for the moment only to free it again so that it can remain alive. Theorizing language as a stable system not only freezes language allowing it to be grasped, but kills it. Focusing on the semantic and syntactic features of language in science classrooms makes us blind to the dynamically and continuously changing dimensions of language-in-use, which may be completely independent of the dictionary sense of the words in play.

\section{References}

Aguilar, O. G., Mortimer, E. F., \& Scott, P. (2010). Learning from and responding to students' questions: The authoritative and dialogic tension. Journal of Research in Science Teaching, 47, 174-193.

Alonzo, A. C., Kobarg, M., \& Seidel, T. (2012). Pedagogical content knowledge as reflected in teacherstudent interactions: Analysis of two video cases. Journal of Research in Science Teaching, 49, 12111239.

Baker, D. (2013). What works: Using curriculum and pedagogy to increase girls' interest and participation in science. Theory Into Practice, 52, 14-20.

Bakhtin, M. M. (1975). Voprosy literatury i estetiki [Problems in literature and aesthetics]. Moscow, Russia: Xudoš. Lit. (English: The dialogic imagination, Austin, TX: University of Texas, 1981.) Bakhtin, M. M. (1979). Estetika slovesnogo tvorčestva [Aesthetics of verbal creation]. Moscow, Russia: 
Iskusstvo. (French: Esthétique de la creation verbale, Éditions Gallimard, Paris, France, 1984)

Bakhtin, M. M. (1990). Tvorčestvo Fransua Rable i narodnaja kul'tura srednevekov'ja i Renessansia [The work of François Rabelais and popular culture of the Middle Age and Renaissance ]. Moscow, Russia : Xudošestvennaja literatura. (French : L'œuvre de François Rabelais et la culture au Moyen Age et sous la Renaissance, Paris, France, Gallimard, 1970.) (First published in 1965.)

Bakhtin, M. M. (1994). Problemy poètiki tvorčestvogo Dostoevskogo [Problems of the poetics in the work of Dostoevsky]. Kiev, Russia: Next. (Parts reproduced in the English: Problems of Dostoevsky’s poetics, Minneapolis, MI, University of Minneapolis Press, 1984) (First published in 1929)

Bellocchi, A., \& Ritchie, S. M. (2011). Investigating and theorizing discourse during analogy writing in chemistry. Journal of Research in Science Teaching, 48, 771-792.

Chi, M. T. H. (1992). Conceptual change within and across ontological categories: Examples from learning and discovery in science. In R. Giere (Ed.), Cognitive models of science: Minnesota studies in the philosophy of science (pp. 129-186). Minneapolis: University of Minnesota Press.

Durkheim, E. (1919). Les règles de la méthode sociologique septième édition 7ième ed. [Rules of sociological method 7th ed.]. Paris, France: Felix Alcan.

El-Hani, C. N., \& Mortimer, E. F. (2007). Multicultural education, pragmatism, and the goals of science teaching. Cultural Studies in Science Education, 2, 657-702.

Falk, J. H., \& Needham, M. D. (2011). Measuring the impact of a science center on its community. Journal of Research in Science Teaching, 48, 1-12.

Ford, M. J., \& Wargo, B. M. (2012). Dialogic framing of scientific content for conceptual and epistemic understanding. Science Education, 96, 369-391.

Garfinkel, H. (1967). Studies in ethnomethodology. Englewood Cliffs, NJ: Prentice-Hall.

Garfinkel, H., \& Sacks, H. (1986). On formal structures of practical action. In H. Garfinkel (Ed.), Ethnomethodological studies of work (pp. 160-193). London: Routledge \& Kegan Paul.

Gee, J. P. (2005). Language in the science classroom: Academic social languages as the heart of schoolbased literacy. In R. Yerrick \& W.-M. Roth (Eds.), Establishing scientific classroom discourse 
communities: Multiple voices of teaching and learning research (pp. 19-37). Mahwah, NJ: Lawrence Erlbaum Associates.

Hsu, P.-L. (2012). Understanding creative cultural divergence: A Bakhtinian reflection from a culturecrossing scholar. Cultural Studies in Science Education, 7, 103-110.

Hsu, P.-L., \& Roth, W.-M. (2012). From authoritative discourse to internally persuasive discourse: discursive evolution in teaching and learning the language of science. Cultural Studies of Science Education. DOI 10.1007/s11422-012-9475-2

Hsu, P.-L., Roth, W.-M., Marshall, A., \& Guenette, F. (2009). To be or not to be? Discursive resources for (dis)identifying with science-related careers. Journal of Research in Science Teaching, 46, 11141136.

Husserl, E. (1939). Die Frage nach dem Ursprung der Geometrie als intentional-historisches Problem [The question about the origin of geometry as intentional-historical problem]. Revue Internationale de Philosophie, 1, 203-225.

Il'enkov, E. V. (1959). Dialektika abstraktnogo i konkretnogo v «Kapitale» Marksa [Dialectics of the abstract and the concrete in Marx's "Capital"]. Moscow, USSR: Akademii nauk CCCP. (English: Progress, Moscow, 1982)

Kane, J. M. (2012). Young African American children constructing academic and disciplinary identities in an urban science classroom. Science Education, 96, 457-487.

Kelly, G. J., \& Sezen, A. (2010). Activity, discourse, \& meaning: Some directions for science education. In W.-M. Roth (Ed.), Re/structuring science education: ReUniting sociological and psychological perspectives (pp. 39-52). Dordrecht, The Netherlands: Springer.

Knaggs, C. M., \& Schneider, R. M. (2012). Thinking like a scientist: Using vee-maps to understand process and concepts in science. Research in Science Education, 42, 609-632.

Kuhn, T. S. (1970). The structure of scientific revolutions (2nd ed.). Chicago, IL: University of Chicago Press.

Lara-Alecio, R., Tong, F., Irby, B. J., Guerrero, C., Huerta, M., Fan, Y. (2012). The effect of an instructional intervention on middle school English learners' science and English reading 
achievement. Journal of Research in Science Teaching, 49, 987-1011.

Lehesvuori, S., Viri, J., Rasku-Puttonen, H., Moate, J., \& Helaakoski, J. (2013). Visualizing communication structures in science classrooms: Tracing cumulativity in teacher-led whole class discussions. Journal of Research in Science Teaching, 50, 912-939.

Lemke, J. L. (1990). Talking science: Language, learning and values. Norwood, NJ: Ablex.

Leont'ev, A. A. (1969). Jazyk, rec', recevaja dejatel'nost'. Moscow, USSR: Prosveščenje. (German: Sprache, Sprechen, Sprechtätigkeit, C. Heeschen, Trans., Stuttgart, Germany: Kohlhammer, 1971.)

Levinas, E. (1971). Le dit et le dire [The said and the saying]. Le Nouveau Commerce, 18/19, 21-48.

Linell, P. (2006). Towards a dialogical linguistics. In M. Lähteenmäki, H. Dufva, S. Leppänen \& P. Varis (Eds.), Proceedings of the XIIth International Bakhtin Conference (pp. 157-172). Jyväskylä, Finland: University of Jyväskylä.

Lyon, E. G., Bunch, G. C., \& Shaw, J. M. (2012). Navigating the language demands of an inquiry-based science performance assessment: Classroom challenges and opportunities for English learners. Science Education, 96, 631-651.

Marx, K./Engels, F. (1958). Werke 3 [Works vol. 3]. Berlin, Germany: Dietz. (Written in 1846)

McClary, L., \& Talanquer, V. (2011). College chemistry students' mental models of acids and acid strength. Journal of Research in Science Teaching, 48, 396-413.

McNeill, K. (2011). Elementary students' views of explanation, argumentation, and evidence, and their abilities to construct arguments over the school year. Journal of Research in Science Teaching, 48, $793-823$.

Merleau-Ponty, M. (1945). Phénoménologie de la perception [Phenomenology of perception]. Paris, France: Gallimard.

Mikhailov, F. T. (1980). The riddle of self. Moscow: Progress Publishers.

Nielsen, J. A. (2012). Science in discussions: An analysis of the use of science content in socioscientific discussions. Science Education, 96, 428-456.

Oliveira, A., W., Akerson, V. L., Colak, H., Pongsanon, K., \& Genel, A. (2012). The implicit communication of nature of science and epistemology during inquiry discussions. Science Education, 
$96,652-684$.

Ong, W. J. (1982). Orality and literacy: The technologizing of the word. New York, NY: Routledge.

Polman, J. L., \& Hope, J.M.G. (2014). Sciences news stories as boundary objects affecting engagement with science. Journal of Research in Science Teaching, 51, 315-341.

Poole, D. (1994). Routine testing practices and the linguistic construction of knowledge. Cognition and Instruction, $12,125-150$.

Richardson-Bruna, K., Vann, R., \& Escudero, M. P. (2007). What's language got to do with it?: A case study of academic language instruction in a high school "English Learner Science" class. Journal of English for Academic Purposes, 6, 36-54.

Richardson-Bruna, K., \& Gomez, K. (Eds.). (2009). The work of language in multicultural classrooms: Talking science, writing science. New York, NY: Routledge.

Ricoeur, P. (1986). Du texte à l'action: Essais d'herméneutique II [From text to action: Essays in hermeneutics II]. Paris: Éditions du Seuil.

Rorty, R. (1989). Contingency, irony, and solidarity. Cambridge, UK: Cambridge University Press.

Roth, W.-M. (2005). Talking science: Language and learning in science. Lanham, MD: Rowman \& Littlefield.

Roth, W.-M. (2008a). Bricolage, métissage, hybridity, heterogeneity, diaspora: Concepts for thinking science education in the 21st century. Cultural Studies in Science Education, 3, 891-916.

Roth, W.-M. (2008b). The nature of scientific conceptions: A discursive psychological perspective. Educational Research Review, 3, 30-50.

Roth, W.-M. (2009). Dialogism: A Bakhtinian perspective on science and learning. Rotterdam, The Netherlands: Sense Publishers.

Roth, W.-M. (2010a). Language, learning, context: Talking the talk. London, UK: Routledge.

Roth, W.-M. (2010b). Thinking and speaking: A dynamic approach. In W.-M. Roth (Ed), ReUniting sociological and psychological perspectives (pp. 113-143). Dordrecht, The Netherlands: Springer.

Roth, W.-M. (2013a). Technology and science in classroom and interview talk with Swiss lower secondary school students: a Marxist sociological approach. Cultural Studies of Science Education, 8, 
$433-465$.

Roth, W.-M. (2013b). To event: Towards a post-constructivist approach to theorizing and researching curriculum as event*-in-the-making. Curriculum Inquiry, 43, 388-417.

Roth, W.-M. (2013c). An integrated theory of thinking and speaking that draws on Vygotsky and Bakhtin/Vološinov. Dialogical Pedagogy, 1, 32-53.

Roth, W.-M. (2013d). Toward a post-constructivist ethics in/of teaching and learning. Pedagogies: An International Journal, 8, 103-125.

Roth, W.-M. (2013e). What more? in/for science education: An ethnomethodological perspective. Rotterdam, The Netherlands: Sense Publishers.

Roth, W.-M. (in press-a). At the intersection of text and talk: On the reproduction and transformation of language in the multilingual evaluation of multilingual texts. Semiotica.

Roth, W.-M. (in press-b). Learning in the discovery sciences: The history of a "radical" conceptual change or The scientific revolution that was not. Journal of the Learning Sciences. DOI: $10.1080 / 10508406.2014 .893435$

Roth, W.-M., \& Jornet, A. G. (2013). Situated cognition. WIREs Cognitive Science, 4, xxx-xxx. doi: $10.1002 /$ wcs. 1242

Roth, W.-M., Lee, Y. J., \& Boyer, L. (2008). The eternal return: Reproduction and change in complex activity systems - The case of salmon enhancement. Berlin, Germany: Lehmanns Media.

Roth, W.-M., \& Lucas, K. B. (1997). From "truth" to "invented reality": A discourse analysis of high school physics students' talk about scientific knowledge. Journal of Research in Science Teaching, $34,145-179$.

Roth, W.-M., Ritchie, S. M., Hudson, P., \& Mergard, V. (2011). A study of laughter in science lessons. Journal of Research in Science Teaching, 48, 437-458.

Roth, W.-M., \& Roychoudhury, A. (1992). The social construction of scientific concepts or The concept map as conscription device and tool for social thinking in high school science. Science Education, 76, $531-557$.

Roth, W.-M., \& Tobin, K. (2010). Solidarity and conflict: Aligned and misaligned prosody as a 
transactional resource in intra- and intercultural communication involving power differences. Cultural Studies of Science Education, 5, 805-847.

Sampson, V., \& Walker, J. P. (2012). Argument-driven inquiry as a way to help undergraduate students write to learn by learning to write in chemistry. International Journal of Science Education, 34, 14431485.

Schegloff, E. (2007). Sequence organization in interaction: A primer in conversation analysis vol. 1. Cambridge, UK: Cambridge University Press.

Schickore, J. (2008). Doing science, writing science. Philosophy of Science, 75, 323-343.

Siry, C., Ziegler, G., \& Max, C. (2012). "Doing science” through discourse-in-interaction: Young children's science investigations at the early childhood level. Science Education, 96, 311-336.

Tomas, L., Ritchie, S. M., \& Tones, M. (2011). Attitudinal impact of hybridized writing about a socioscientific issue. Journal of Research in Science Teaching, 48, 878-90.0

Treagust, D. F., \& Duit, R. (2008). Conceptual change: A discussion of theoretical, methodological and practical challenges for science education. Cultural Studies of Science Education, 3, 297-328.

van Eijck, M., \& Roth, W.-M. (2011). Cultural diversity in science education through novelization: Against the epicization of science and cultural centralization. Journal of Research in Science Teaching, 48, 824-847.

Varelas, M., Kane, J. M., \& Wylie, C. D. (2011). Young African American children's representations of self, science, and school: Making sense of difference. Science Education, 95, 824-851.

Varelas, M., Kane, J. M., \& Wylie, C. D. (2012). Young black children and science: Chronotopes of narratives around their science journals. Journal of Research in Science Teaching, 49, 568-596.

Vološinov, V. N. (1930). Marksizm i folosofija jazyka : osnovye problemy sociologičeskogo metoda b nauke o jazyke [Marxism and the philosophy of language : Main problems of the sociological method in linguistics]. Leningrad, USSR : Priboj. (French: Bakhtine, M. [Volochinov, V. N.] (1977). Le marxisme et la philosophie du langage: Essai d'application de la méthode sociologique en linguistique. Paris, France: Les Éditions de Minuit.)

Vygotskij, L. S. (1983). Sobranie sočinenij tom četveryj : Detskaja psixologija [Works vol. 4 : Child 
psychology]. Moscow, USSR : Pedagogika.

Vygotskij, L. S. (2005). Psyxhologija razvitija čeloveka [Psychology of human development]. Moscow, Russia: Eksmo. (Quotations from the chapter Thinking and Speaking have been checked against the German version Denken und Sprechen, 2002, Weinheim, Germany, Beltz)

Waldenfels, B. (2006). Grundmotive einer Phänomenologie des Fremden [Fundamental ideas of a phenomenology of the foreign/strange]. Frankfurt/M, Germany: Suhrkamp.

Wells, G. (2007). The linguistic construction of expert identity in professor-student discussions of science. Cultural Studies in Science Education, 2, 151-170.

Wittgenstein, L. (1997). Philosophische Untersuchungen / Philosophical investigations (2nd ed.). Oxford, UK: Blackwell.

Zeyer, A., \& Roth, W.-M. (2013). Post-ecological discourse in the making. Public Understanding of Science, $22,33-48$. 


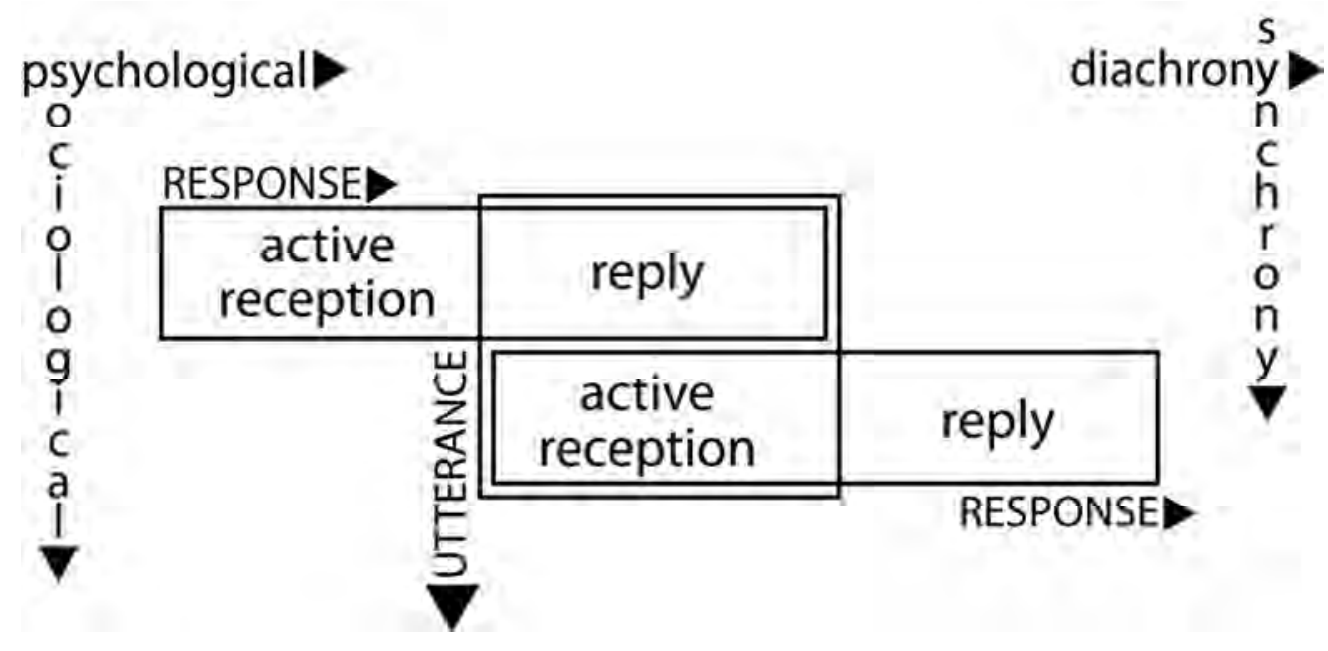

Figure 1. A model of the sympractical speech situation. The two horizontal levels correspond to two consecutive speakers. $100 \times 48 \mathrm{~mm}$ (300 x 300 DPI) 


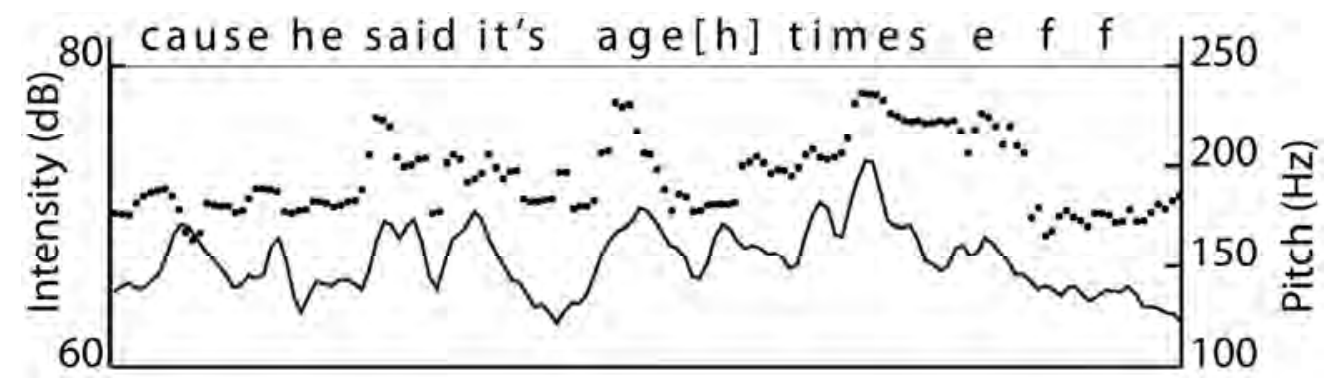

Figure 2. Although the characteristic "that" marking indirect reported speech is missing, the prosodic parameters (speech intensity, speech rate, pitch) are typical for indirect reported speech.

$123 \times 34 \mathrm{~mm}(300 \times 300 \mathrm{DPI})$ 


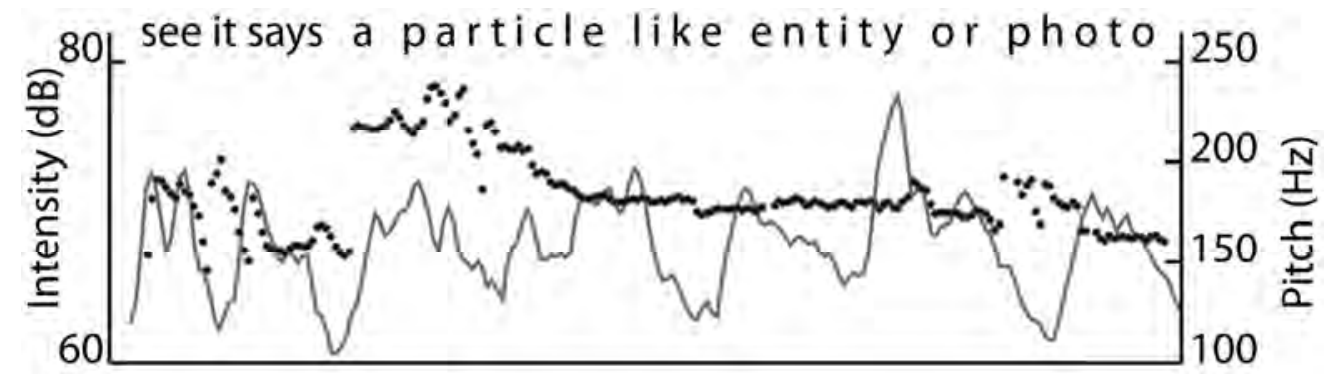

Figure 3. Intonation that sets the direct quotation (direct discourse) apart from the reporting discourse ("see it says").

$123 \times 34 \mathrm{~mm}(300 \times 300 \mathrm{DPI})$ 


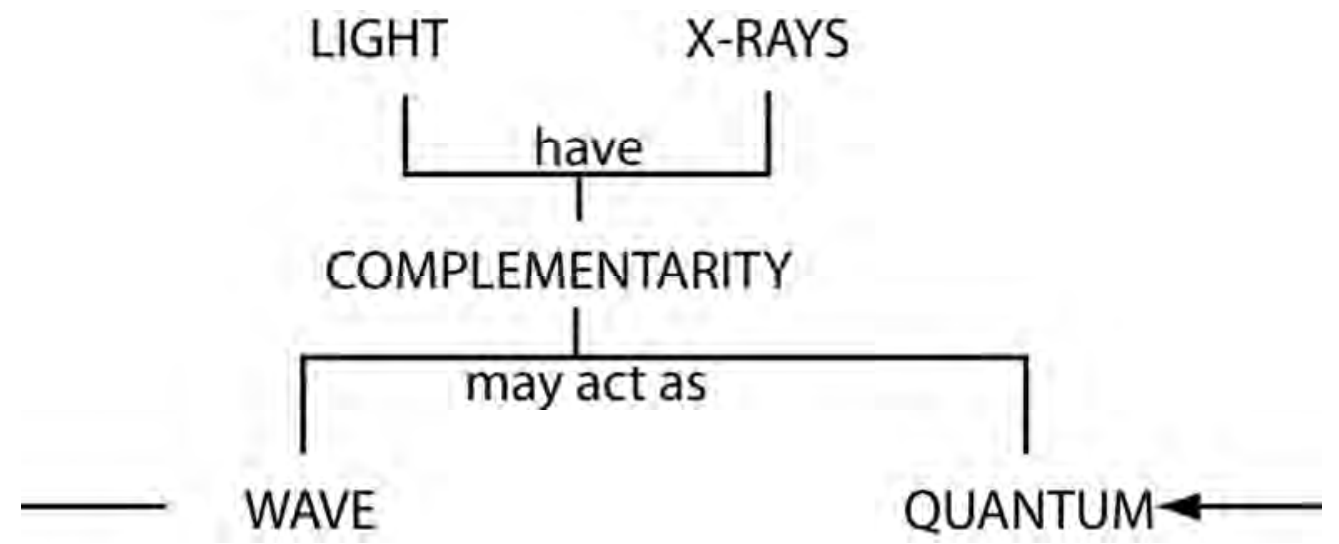

Figure 4. Final configuration that connects "complementarity" to other terms $82 \times 33 \mathrm{~mm}(300 \times 300$ DPI $)$ 


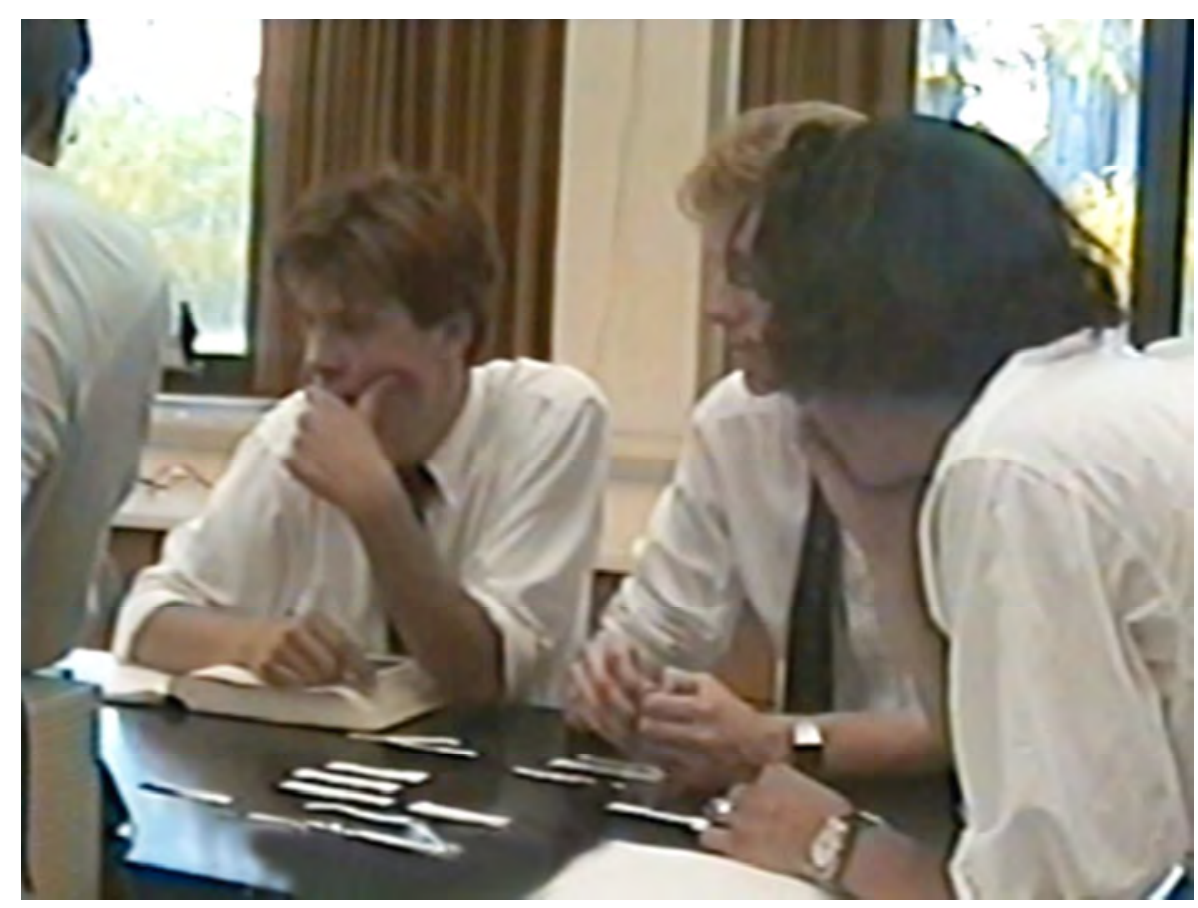

This figure has no caption. It goes into the transcription. $38 \times 28 \mathrm{~mm}(300 \times 300 \mathrm{DPI})$ 